\title{
How Many People Live in Politically Partisan Online News Echo Chambers in Different Countries?
}

\author{
RICHARD FLETCHER \\ CRAIG T. ROBERTSON \\ RASMUS KLEIS NIELSEN \\ University of Oxford, UK
}

Concern over online news echo chambers has been a consistent theme in recent debates on how people get news and information. Yet, we lack a basic descriptive understanding of how many people occupy bounded online news spaces in different countries. Using online survey data from seven countries we find that (i) politically partisan left-right online news echo chambers are real, but only a minority of approximately $5 \%$ of internet news users inhabit them, (ii) in every country covered, more people consume no online news at all than occupy partisan online echo chambers, and (iii) except for the US, decisions over the inclusion or exclusion of particular news outlets make little difference to echo chamber estimates. Differences within and between media systems mean we should be very cautious about direct comparisons between different echo chambers, but underlying patterns of audience overlap, and the continued popularity of mainstream outlets, often preclude the formation of large partisan echo chambers.

Keywords: echo chambers, selective exposure, algorithmic selection, news audiences, polarization

\footnotetext{
Richard Fletcher: richard.fletcher@politics.ox.ac.uk Date submitted: 2021-01-07

Copyright @ 2021 (Fletcher, Robertson, Nielsen). Licensed under the Creative Commons Attribution Noncommercial No Derivatives (by-nc-nd). Available at: http://journalqd.org
} 
Since 2010, the term "echo chamber" has increasingly been used in public debate, policy circles, and academic research to describe situations where people only hear opinions of one type. ${ }^{1}$ People worry about echo chambers because they fear they will fuel political fragmentation and polarization, diminish mutual understanding, and ultimately lead to a situation where people are so far apart that they have no common groundeffectively inhabiting different political realities (Kim, 2015; Kreiss, 2017; Lawrence et al., 2010; Sunstein, 2017; Van Aelst et al., 2017).

Much important work has been done on this topic, such as identifying the different mechanisms that might lead people into echo chambers - including selective exposure and algorithmic ranking (e.g., Flaxman et al., 2016; Garrett, 2009; Jamieson \& Cappella, 2008). But so far, as Tucker et al. (2018, p. 55) point out, there have been few attempts to operationalize and measure the prevalence of echo chambers at the national level using representative samples (for partial exceptions, see Dubois \& Blank, 2018; Dvir-Gvirsman et al., 2016; Boulianne et al., 2020).

This means we lack a basic descriptive, empirical understanding of a substantively important and frequently discussed question in communications research and the media. We address this shortcoming by estimating how many people live in politically partisan online news echo chambers in seven different countries, based on data from online surveys with nationally representative samples of news users $(\mathrm{N} \approx 2000$ per country). In each country, we estimate the percentage who say they only get news from left-wing or rightwing online news outlets in that country, identified using 'audience-based' measures of outlet slant (Flaxman et al., 2016). However, because choices about what subset of outlets are considered sufficiently left- or right-leaning to constitute an echo chamber are often arbitrary, subject to bias, and bitterly contested - and to go beyond the confusion that reflects that there is no one, single, objective and agreed-upon way to define and

\footnotetext{
${ }^{1}$ For example, see: Google Ngram Viewer: '[Echo chamber]', 1800-2019 in English. https://books.google.com/ngrams/graph?content=Echo+chamber\&year_start=1800\&year_end=2019\&corp $\underline{\text { us }=26 \& \text { smoothing }=3 \&}$
} 
operationalize what exactly constitutes a partisan source-we estimate the average size of echo chambers across multiple subsets of outlets in the data. This, we argue, helps mitigate the effect of researcher degrees of freedom on echo chamber estimates, and highlights cases where decisions about what outlets to include are the most consequential.

Using online survey data from seven countries (Austria, Denmark, Germany, Norway, Spain, UK, US) we find that (i) politically partisan online news echo chambers are real, but, in most countries covered, only a minority of approximately $5 \%$ of internet users inhabit them, and (ii) in every country covered, many more internet users consume no online news at all on a regular basis than inhabit echo chambers. Finally, (iii) in most cases we find that decisions over whether to include or exclude particular news outlets make little difference to echo chamber estimates. The clearest exception is the left-leaning online news echo chamber in the US, where decisions about whether to include outlets with strongly left-leaning audiences can move the estimated size from anywhere between 0 and around $30 \%$ of the population.

While we sometimes see estimates of different sizes both between countries and left and right echo chambers within countries, we should be very cautious about comparisons between groups of outlets that differ markedly in the journalistic practices they use and the content they produce (Benkler et al., 2018). The substantial implications of a given politically partisan echo chamber fundamentally depends on what messages are amplified.

We argue that our findings help provide an important empirical grounding for discussions around echo chambers by measuring their prevalence, and they remind us that information inequality driven by limited engagement with news — and sometimes outright news avoidance - is a more widespread feature of our online environment than politically partisan online news echo chambers. 


\section{Echo Chambers}

Our analysis is focused specifically on politically partisan online news echo chambers. This is a particular instantiation of what Jamieson and Capella in their influential book Echo Chamber defined as "a bounded, enclosed media space that has the potential to both magnify the messages delivered within it and insulate them from rebuttal" (2008, p. 76).

It is important to recognize that our focus on politically partisan online news echo chambers is particular and specific. Even in scientific work, the term echo chamber remains more a multi-faceted metaphor than a single, clearly defined and agreed-upon concept. While Jamieson and Capella, like us, were interested in politically partisan news echo chambers (their main focus was on offline media, especially Fox News television, rightwing talk radio, and the editorial pages of the Wall Street Journal), scholars have used the term much more broadly - e.g., to describe the news institution as a whole as "the media echo chamber" (Bennett et al., 2008) — as well as more narrowly - for example focusing on how political journalists affiliated with mainstream media use blogs (Singer, 2005), or with a focus on social media rather than news media (Barberá et al., 2015). It is equally important to note that because we seek to measure the prevalence of politically partisan online news echo chambers specifically, we will not consider how many live in a centrist echo chamber and leave aside the question of the prevalence of other types of echo chambers not associated with partisan politics (e.g., around class or identity) or with political cleavages poorly aligned with left-right distinctions.

Because our main aim here is descriptive and empirical, to operationalize politically partisan online news echo chambers and measure their prevalence in different countries, we will also leave it for the reader to pass normative and moral judgement on the implications of our results. However, we would like to acknowledge that while often taken to mean something problematic, sometimes what one person may see as a problematic echo chamber is another person's promising counter-public (Jackson et al., 2020). Simply put, 
people living in an echo chamber that magnifies messages you approve of may strike you as relatively benign, whereas people living in one that magnifies messages you disapprove of may feel more pernicious.

This also means there is no reason to expect equivalence in echo chambers between or within countries. Content from right-leaning sources in the UK might be different from those in Germany, for example, and as others have already argued, left-leaning and rightleaning outlets in the US adopt fundamentally different editorial practices (Benkler et al., 2018). Either way, these judgements are separate from descriptions of patterns of media use. For similar reasons, our analysis does not consider whether exposure is cross-cutting or not (e.g., people who identify as right-wing accessing news from left-leaning outlets). Although cross-cutting news exposure is often considered beneficial (Mutz, 2006), some research finds that it can increase polarization (Bail et al., 2018), so we leave this for future work.

\section{Literature Review}

Before turning to our operationalization of politically partisan online news echo chambers and estimates of their prevalence in different countries, let us briefly outline the main causal mechanisms that might lead people into such bounded, enclosed media spaces. Scholars highlight two main factors: selective exposure and algorithmic selection.

\section{Selective Exposure}

The basic theory of selective exposure is that individuals find it more psychologically comforting to voluntarily expose themselves to information aligned with their pre-existing attitudes and beliefs (Sears \& Freedman, 1967), prompting them to selectively expose themselves to agreeable sources. Furthermore, partisans may see news from agreeable sources as more credible and base their selections on this criterion (Metzger et al., 2020). Prior work has demonstrated tendencies for selective exposure to attitudinally 
congruent information under experimental conditions (Hameleers et al., 2018; Iyengar \& Hahn, 2009) and has shed light on partisan network homophily on social media platforms (Barberá et al., 2015; Williams et al., 2015; Del Vicario et al., 2016).

However, while individuals do practice selective exposure, they do not necessarily always engage in selective avoidance (Garrett, 2009, 2013; Garrett \& Stroud, 2014; Johnson et al., 2011; Kim \& Lu, 2020; Weeks et al., 2016). In other words, consumers of partisan news sources often also consume news from neutral and counter-attitudinal sources, effectively bursting their bubble (Garrett et al., 2013). In some cases, this may be because interest in news and politics are more determinative in news exposure than political ideology (Dahlgren, 2019; Garrett et al., 2013; Skovsgaard et al., 2016; Van Aelst et al., 2017; Yang et al., 2020).

\section{Algorithmic Selection}

The recent growth of social media, search engines, and news aggregators has - due to their reliance on algorithmic selection - further complicated our understanding of what drives news exposure online. While early internet use could primarily be understood through selective exposure, platforms like search engines, social networks, and news aggregators combine self-selection with algorithmic selection to different extents. Put differently, usage patterns on platforms are a mixture self-selected personalization that people do themselves and involuntary "pre-selected personalization" resulting from algorithmic selection (Zuiderveen Borgesius et al., 2016).

Echo chambers thought to primarily result from pre-selected personalization are sometimes called filter bubbles (Pariser, 2011) — but these terms overlap, are often used interchangeably, and the normative concerns are much the same. So far, there is little evidence of filter bubble effects specifically (Bruns, 2019). While some studies do find evidence of non-random exposure to news and information on algorithmically-driven platforms (Bakshy et al., 2015), it is often difficult to disentangle the effects of pre-selected 
personalization from self-selected personalization, so the role of algorithmic selection specifically remains unclear. To complicate matters further, research on social media must also consider the makeup of people's social networks. Although people tend to commune and communicate with similar others (McPherson et al., 2001), social networks often consist of weak ties, and there is evidence that social endorsements actually counteract partisan selective exposure (Messing \& Westwood, 2014).

Algorithmic selection may also be counteracting selective exposure if it exposes people to news from sources they would not normally use. Incidental exposure to news on social media, and automated serendipity from search engines and aggregators, means that people who use these services have more diverse news repertoires than people that only go to websites directly (Cardenal et al., 2019; Flaxman et al., 2016; Fletcher et al., 2021; Fletcher \& Nielsen, 2018a, 2018b; Scharkow et al., 2020). This suggests that even if algorithmic selection is not completely random (or even particularly diverse), it may still be more diverse than self-selection - meaning that the net effect would be to lower people's likelihood of being in an echo chamber rather than raise it. Studies like these-which compare across platforms - highlight the danger of drawing broad conclusions based on data from single platform studies, because this data cannot be interpreted in light of people's other media use (Dubois \& Blank, 2018). It is hard to see how someone who primarily follows and interacts with a clearly partisan set of accounts on Twitter but in parallel uses several different sources of online news and comes across a diverse range of sources via search and other social media can be said to be in an echo chamber, or how studies of Twitter alone - or any other platform in isolation - would allow one to determine if the person in question inhabits an echo chamber. Indeed, evidence from the US has shown that some who experience little or no cross-cutting exposure on Twitter still encounter opposing views via television news - suggesting that analysis of echo chambers based on Twitter data alone will overestimate their size (Eady et al., 2019). 


\section{The Size of Partisan News Echo Chambers}

All of this may partly explain why research overall indicates that most people have relatively diverse news repertoires and that few are likely to be in entirely one-sided news echo chambers. Studies of media use in the US have found that while people do consume ideologically agreeable content, they also consume some news from the 'other side', with audiences often converging on large mainstream news outlets and middle-ground local news sources (Flaxman et al., 2016; Nelson \& Webster, 2017; Prior, 2013; Webster \& Ksiazek, 2012; Wicks et al., 2014; Yang et al., 2020). Similar patterns have been observed in Sweden (Dahlgren et al., 2019), Hong Kong (Chen et al., 2020), Spain (Masip et al., 2020), Austria (Trilling \& Schoenbach, 2015), Israel (Dvir-Gvirsman et al., 2016), the Netherlands (Bos et al., 2016) and other high-income democracies (Fletcher \& Nielsen, 2017). Across news sources, there are often "very high levels of audience overlap," meaning there is "little evidence of ideological segmentation in media use" (Webster \& Ksiazek, 2012, p. 50). Gentzkow and Shapiro (2011, p. 1831) observe that "internet news consumers with homogeneous news diets are rare" and Garrett (2013, p. 248) says the notion that large numbers are cocooned in pure ideological news echo chambers, cut off from other points of view, is exaggerated and wrong (see also Van Aelst et al., 2017, p. 14).

Although we have good reasons to expect online echo chambers to be small, we lack estimates of their size. There have, however, been attempts to estimate how many people engage in partisan selective exposure and/or experience cross-cutting exposure (e.g. Prior, 2013; Stroud, 2011). Eady et al. (2019) linked Twitter and survey data from the US to produce various estimates of the proportion that experienced cross-cutting exposure on Twitter. They showed that $65 \%$ of those in the most Conservative quintile potentially saw news tweets from outlets to the left of the New York Times, while 27\% of the most Liberal users potentially saw news outlets to the right of Fox News (with higher numbers if measures of television use from survey data are included)-thus suggesting that Conservatives are more likely to experience cross-cutting exposure than Liberals. 
Although it could be argued that anyone who does not experience cross-cutting exposure is in an echo chamber, such a definition will likely overestimate the size of echo chambers because it does not account for exposure to more centrist outlets that may also offer different (and sometimes opposing) viewpoints. Estimates of the size of echo chambers defined through partisan homogeneity (i.e., only using news outlets of a particular partisan leaning) are rarer — and even those that exist are not directly comparable due to differences in how they are operationalized. Some have used survey research to ask people about perceptions of media exposure. In the UK, for example, Dubois and Blank (2018) found that around 10\% said they almost never see political content on social media that they disagree with, while around $15 \%$ said they never use outlets outside of their normal repertoire. Boulianne et al. (2020) asked similar questions in the UK, US, and France, and found that around $25-30 \%$ said they never encountered political information that represented an opposing view online or offline, with higher figures for offline and social media discussion. Other estimates have been based on measuring people's media repertoires directly. Dvir-Gvirsman and colleagues (2016), based on web tracking data in Israel, found that only $3 \%$ of individuals were in partisan news echo chambers. Similarly, based on web tracking data, Fletcher et al. (2020) found that during the six-week 2019 General Election campaign in the UK, just $4 \%$ of Conservative voters and $2 \%$ of Labour voters only used online news sources that had openly endorsed their preferred party.

The patchiness of this evidence is problematic because there are reasons to expect that the size of online news echo chambers will vary by country. In addition to the fact that there is a long tradition of comparative research that highlights fundamental differences in national media systems (Hallin \& Mancini, 2004), empirical research has found sizable variation in the extent of news audience polarization (Fletcher et al., 2020), selective exposure (Castro-Herrero et al., 2018), and media-party parallelism (van Kempen, 2007).

On this basis, we ask one broad research question: What proportion of people live in partisan online news echo chambers in different countries? 


\section{Method}

We answer this question using data from the 2020 Reuters Institute Digital News Report (Newman et al., 2020) — an online survey of news users fielded by YouGov and their partners in late January and early February 2020. Nationally representative, nonprobability samples of around 2,000 respondents were assembled using quotas for age, gender, education, and region in every country. The very small number of respondents that said they did not consume any news in the last month were screened out at the beginning. The countries included in the present study are listed in Table 1, along with descriptive statistics.

The main advantage of using this dataset is that the same questions (described below) were fielded at the same time, in the same way, in all countries. A key limitation, however, is that online surveys are dependent on recall for measuring online news use and are thus subject to biases themselves associated with demographic variables (Prior, 2009). Surveys tend to produce different individual-level data on media use compared to, for example, passive web tracking (Guess, 2015).

The data we use in the analysis that follows come from four questions. The first asked "Which of the following brands have you used to access news online in the last week (via websites, apps, social media, and other forms of Internet access)?" Respondents selected from a list of around 30 of the most popular online news brands in each country. In addition, the survey asked people about their use of around six newer, alternative/partisan brands (e.g., Breitbart in the US and the Canary in the UK). We asked "In recent years a number of online news sites have emerged with their content often distributed via social media. Which, if any, of the following have you heard of?", then, depending on the responses, "Which, if any, of the following have you used to access news in the last week?" The use of these brands was asked about separately because research often sees them as conceptually distinct from mainstream news sources (Holt et al., 2019). 
JQD:DM 1(2021)

Table 1. Descriptive statistics.

\begin{tabular}{cccccccc}
\hline & AT & DK & DE & NO & ES & UK & US \\
\hline Age & 46.40 & 48.59 & 49.01 & 47.29 & 47.39 & 49.48 & 46.76 \\
Female (\%) & 48.73 & 53.32 & 51.22 & 51.24 & 51.25 & 55.65 & 52.90 \\
Education (\%) & & & & & & & \\
Low & 15.81 & 28.19 & 22.03 & 11.84 & 42.32 & 26.26 & 4.67 \\
Medium & 65.49 & 54.44 & 60.32 & 58.86 & 35.79 & 37.69 & 64.72 \\
High & 18.70 & 17.37 & 17.65 & 29.30 & 21.88 & 36.05 & 30.61 \\
Politics (\%) & & & & & & & \\
Left & 31.02 & 37.94 & 35.36 & 35.07 & 48.55 & 33.76 & 36.01 \\
Center & 30.32 & 16.74 & 33.47 & 15.37 & 16.15 & 18.25 & 21.22 \\
Right & 29.03 & 32.65 & 20.64 & 32.54 & 21.98 & 30.28 & 30.80 \\
Don't know & 9.63 & 12.66 & 10.54 & 17.02 & 13.13 & 17.70 & 11.97 \\
Internet (\%) & 88 & 98 & 96 & 99 & 93 & 95 & 89 \\
N & 2005 & 2061 & 2011 & 2010 & 2006 & 2011 & 2055 \\
\hline
\end{tabular}

Note. Data from the online survey apart from internet penetration which is from Internet World Stats. Low education indicates schooling up to ages 16, medium indicates schooling up to ages 18 and/or professional/tertiary qualifications, and high indicates degree-level.

One of the main limitations of the analysis here is that there is a practical limit on how many outlets can be included in a survey. Lists were assembled by country experts and informed by the results of previous research - but could still contain important omissions. Because they were designed to include the most widely-used brands in each country, the survey did not include local or specialised news outlets, or those (sometimes highly partisan) brands that appear in the so-called long tail of media use. However, because these outlets have low reach by definition, we do not believe that this will have a large effect on our estimates.

We use a seven-point left-right self-placement scale for the audience-based measure of outlet slant. We asked: "Some people talk about 'left', 'right' and 'centre' to 
describe parties and politicians. (Generally, socialist parties would be considered 'left wing' whilst conservative parties would be considered 'right wing'). With this in mind, where would you place yourself on the following scale?", with responses ranging from "Very left-wing", through "Center" to "Very right-wing".

\section{Analysis and Findings}

We are concerned throughout the analysis with politically partisan online news echo chambers specifically but for simplicity's sake will refer hereafter to echo chambers, and to left and right echo chambers depending on their political leaning. Because the prevalence of echo chambers has not yet been operationalized and measured at the national level using representative samples, we benchmark our empirical findings against the number of people who consume little or online news, as they do not report using any of the outlets included in the survey in the last week.

Our starting point for identifying the proportion of people inside left-right echo chambers is the 'audience-based' method for estimating the relative ideological slant of news outlets (Gentzkow \& Shapiro, 2011). This approach uses the political composition of each outlet's audience as a proxy for its relative slant on the basis that the more right-wing (or left-wing) an outlet's audience, the more likely it is to have a right-leaning (or leftleaning) editorial slant (Flaxman et al., 2016). Here, relative outlet slant $s$ is simply:

$$
s=o-p
$$

where $o$ is the mean political leaning of the outlet's cross-platform (online and offline) audience (excluding don't knows) and $p$ is the mean political leaning of the whole sample (excluding don't knows). In other words, relative outlet slant is defined as an outlet's average audience political leaning relative to the average political leaning of the population. Outlets with an online reach of $2 \%$ or less were excluded because so few respondents may not be able to produce reliable slant estimates. 
To address some of the challenges of multi-country analysis, the political leaning variable was recoded into a three-point scale $(-0.5=$ left, $0=$ center, $0.5=$ right $)$ to reduce the effect of national variation in response styles (i.e., the tendency for people in different countries to select responses on scales further from/closer to the midpoint for reasons that have nothing to do with the topic) (Johnson et al., 2005), and we use the difference between outlet audiences and the whole sample average (rather than 0 ) to account for differences in the political make-up of different populations (Fletcher et al., 2020). Therefore, a slant score of -0.5 indicates a very strong left slant, 0 indicates no slant, and 0.5 a very strong right slant.

It is important to stress - as others have (Guess, 2021) — that audience-based outlet slant estimates, even at their best, are relative in that they offer of way of seeing whether an outlet is further to the left or the right of the population-which may itself be left- or right-leaning as opposed to evenly balanced (see Table 1). They do not identify the absolute position of outlets on the left-right spectrum, and because a slant score of 0 represents the average political leaning of the population, it does not necessarily indicate impartial reporting in any absolute sense, just as distance from 0 does not necessarily indicate biased or less true reporting. This is particularly important in cross-country research because what prompts people to identify as left- or right-leaning in the first place will be conditioned by the political context and their views about the other side. Furthermore, audiences for different outlets may not reflect differences in editorial practices, so outlets with similarly positive or negative slant scores should not necessarily be seen right- or left-leaning equivalents of one another (Benkler et al., 2018). It is for this reason that we largely avoid direct comparisons of outlets or echo chambers between countries or within countries (left vs. right). Despite these important limitations, the audience-based method offers a quick, practical way of separating out the more left-leaning outlets from the more right-leaning outlets. Given potential disagreements about the political slant of particular outlets, as well as their degree of slant, this method also serves as a transparent and replicable way to measure the relative slant of different news outlets. 
Table 2. Estimated slant of UK news outlets.

\begin{tabular}{ccc}
\hline Outlet & Relative slant & Online reach (\%) \\
\hline Express & 0.24 & 2.78 \\
MailOnline & 0.18 & 15.91 \\
Sun & 0.15 & 5.67 \\
Telegraph & 0.12 & 7.01 \\
Sky News & 0.11 & 9.75 \\
MSN News & 0.06 & 5.62 \\
ITV News & 0.06 & 3.23 \\
Times & 0.02 & 4.08 \\
BBC News & 0.01 & 47.29 \\
Yahoo! News & -0.02 & 5.42 \\
Financial Times & -0.06 & 2.14 \\
Metro & -0.07 & 4.48 \\
Mirror & -0.10 & 4.53 \\
Economist & -0.15 & 2.04 \\
Lad Bible & -0.17 & 4.18 \\
Guardian & -0.22 & 19.24 \\
BuzzFeed News & -0.23 & 6.22 \\
HuffPost & -0.23 & 6.91 \\
Independent & -0.27 & 6.61 \\
\hline
\end{tabular}

Tables 2 and 3 contain outlet slant scores for the UK and US (see Section 5 of the Appendix for other countries). The scores produced using this method have a high degree of face validity, and the US scores are very strongly correlated $(\mathrm{r}=.93)$ with those from Bakshy et al. (2015) based on large-scale data from Facebook and those generated from Pew (2021) data using the same procedure outlined here $(r=.98)$ (see Section 2, Appendix). 
Table 3. Estimated slant of US news outlets.

\begin{tabular}{ccc}
\hline Outlet & Relative slant & Online reach $(\%)$ \\
\hline Breitbart & 0.32 & 6.47 \\
Fox News & 0.25 & 17.66 \\
Daily Caller & 0.22 & 5.21 \\
Blaze & 0.21 & 5.50 \\
AOL News & -0.03 & 5.74 \\
Yahoo! News & -0.05 & 19.76 \\
MSN News & -0.06 & 11.19 \\
ABC News & -0.06 & 9.93 \\
CBS News & -0.06 & 9.68 \\
Wall Street Journal & -0.08 & 8.61 \\
National Geographic & -0.08 & 4.33 \\
USA Today & -0.10 & 9.10 \\
NBC News & -0.14 & 13.43 \\
BuzzFeed News & -0.17 & 13.87 \\
CNN & -0.19 & 20.19 \\
New York Times & -0.21 & 18.10 \\
Vanity Fair & -0.21 & 3.07 \\
LA Times & -0.22 & 5.64 \\
Occupy Democrats & -0.22 & 4.43 \\
Washington Post & -0.23 & 15.18 \\
HuffPost & -0.24 & 16.06 \\
Vice News & -0.26 & 5.99 \\
NPR & -0.26 & 11.05 \\
New Yorker & -0.26 & 5.50 \\
Upworthy & -0.28 & 2.77 \\
Vox & -0.29 & 8.42 \\
& &
\end{tabular}




\begin{tabular}{ccc} 
Salon & -0.31 & 3.84 \\
Mashable & -0.32 & 2.82 \\
Democracy Now & -0.33 & 3.99 \\
Slate & -0.34 & 5.64 \\
\hline
\end{tabular}

The simplest way of estimating the proportion of people in left or right echo chambers is to identify those respondents that only used a subset of outlets that have the strongest left slants, or only the strongest right slants in the last week. For example, we could define a subset of all outlets with a slant score of 0.12 or higher for the right echo chamber in the UK and compute the proportion in the data that only used either the Telegraph (0.12), the Sun (0.15), MailOnline (0.18), or the Express (0.24). However, any choice of a single subset like this is necessarily arbitrary and carries a risk of bias because researchers could specify a cut-off point that would be more likely to produce a certain result. This is sometimes referred to as researcher degrees of freedom.

To partially mitigate this, we aimed to estimate the size of echo chambers for all possible subsets (i.e., the power set) of left-leaning and right-leaning outlets in each country. We can illustrate how this works with a simplified example of a media system with three right-leaning outlets A, B, and C, and two left-leaning outlets D and E. The eight subsets that constitute the right-wing power set are listed in Table 4. For someone to be considered in an echo chamber for subset number 5, for example, they must use at least one of the outlets in the Subset column (A or B) but none of the outlets in the Excluded column, which is all of the other outlets in the media system (C, D and E). If someone uses $\mathrm{B}$ and $\mathrm{C}$, they would not be in a right echo chamber because outlet $\mathrm{C}$ is not in the subset, despite it being right-leaning. The same would be true for those that use any of the leftleaning outlets (D or E), as these can never appear in any of the possible right-leaning subsets. Note that the power set also includes the empty set. For the empty set the proportion in an echo chamber is always $0 \%$ because there are no outlets that are sufficiently right-leaning. 
Table 4. Example subsets within the power set.

\begin{tabular}{ccc}
\hline N & Subset & Excluded \\
\hline 1 & \{\} & - \\
2 & $\{\mathrm{~A}\}$ & $\mathrm{B}, \mathrm{C}, \mathrm{D}, \mathrm{E}$ \\
3 & $\{\mathrm{~B}\}$ & $\mathrm{A}, \mathrm{C}, \mathrm{D}, \mathrm{E}$ \\
4 & $\{\mathrm{C}\}$ & $\mathrm{A}, \mathrm{B}, \mathrm{D}, \mathrm{E}$ \\
5 & $\{\mathrm{~A}, \mathrm{~B}\}$ & $\mathrm{C}, \mathrm{D}, \mathrm{E}$ \\
6 & $\{\mathrm{~B}, \mathrm{C}\}$ & $\mathrm{A}, \mathrm{D}, \mathrm{E}$ \\
7 & $\{\mathrm{~A}, \mathrm{C}\}$ & $\mathrm{B}, \mathrm{D}, \mathrm{E}$ \\
8 & $\{\mathrm{~A}, \mathrm{~B}, \mathrm{C}\}$ & $\mathrm{D}, \mathrm{E}$ \\
\hline
\end{tabular}

We therefore conduct a form of Specification-Curve Analysis (SCA) because it involves "identifying the set of theoretically justified, statistically valid, and non-redundant analytic specifications" and "displaying alternative results graphically, allowing the identification of decisions producing different results" (Simonsohn et al., 2015). On this basis, we automatically exclude those outlets with very low relative slant scores in the range $(-.05, .05)$ from appearing in right-wing or left-wing subsets, as we do not believe their inclusion is theoretically justified. Outlets within this range typically include aggregator outlets like Yahoo! News and public broadcasters that are required to be impartial like the BBC, meaning they are very unlikely to constitute an echo chamber for most people. In practical terms, excluding these outlets from left-leaning and right-leaning specifications means that anyone who uses them can never be found to be in an echo chamber. Because this exclusion threshold is arbitrary, we also test the effect of using different ranges in Section 3 of the Appendix and discuss the implications in the results section.

Finally, because the number of possible subsets grows exponentially with the number of left- or right-leaning brands included in the surveys in each country (itself depending on market size and population), there is large variation in the number of combinations, ranging from just five for the right echo chamber in Austria to over 3 billion 
for the left echo chamber in the US. Therefore, in the case of the left echo chamber in the US, and the right echo chamber in Spain, 10,000 specifications were randomly selected from a list of all possible subsets to reduce computing time to practical levels.
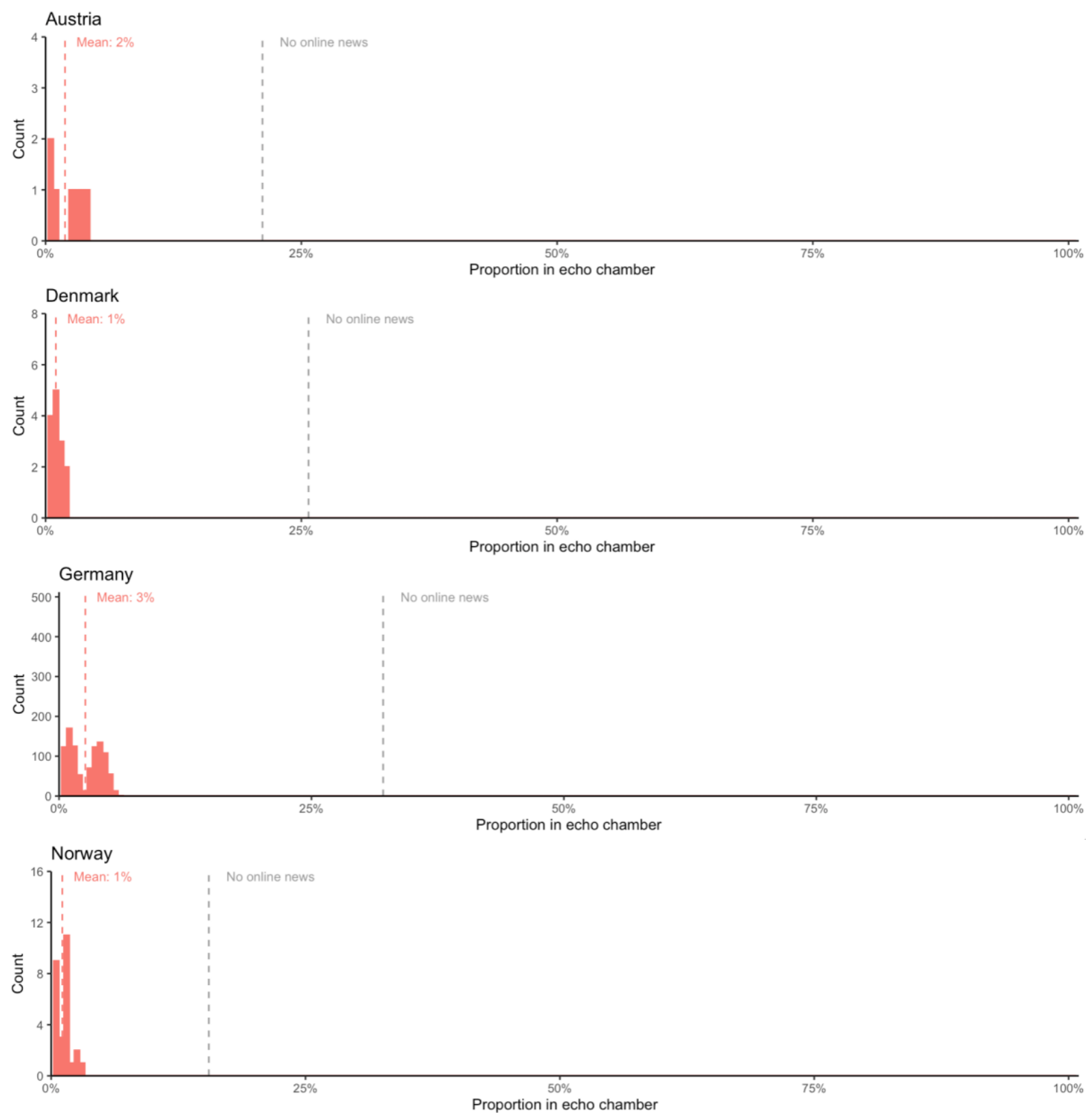

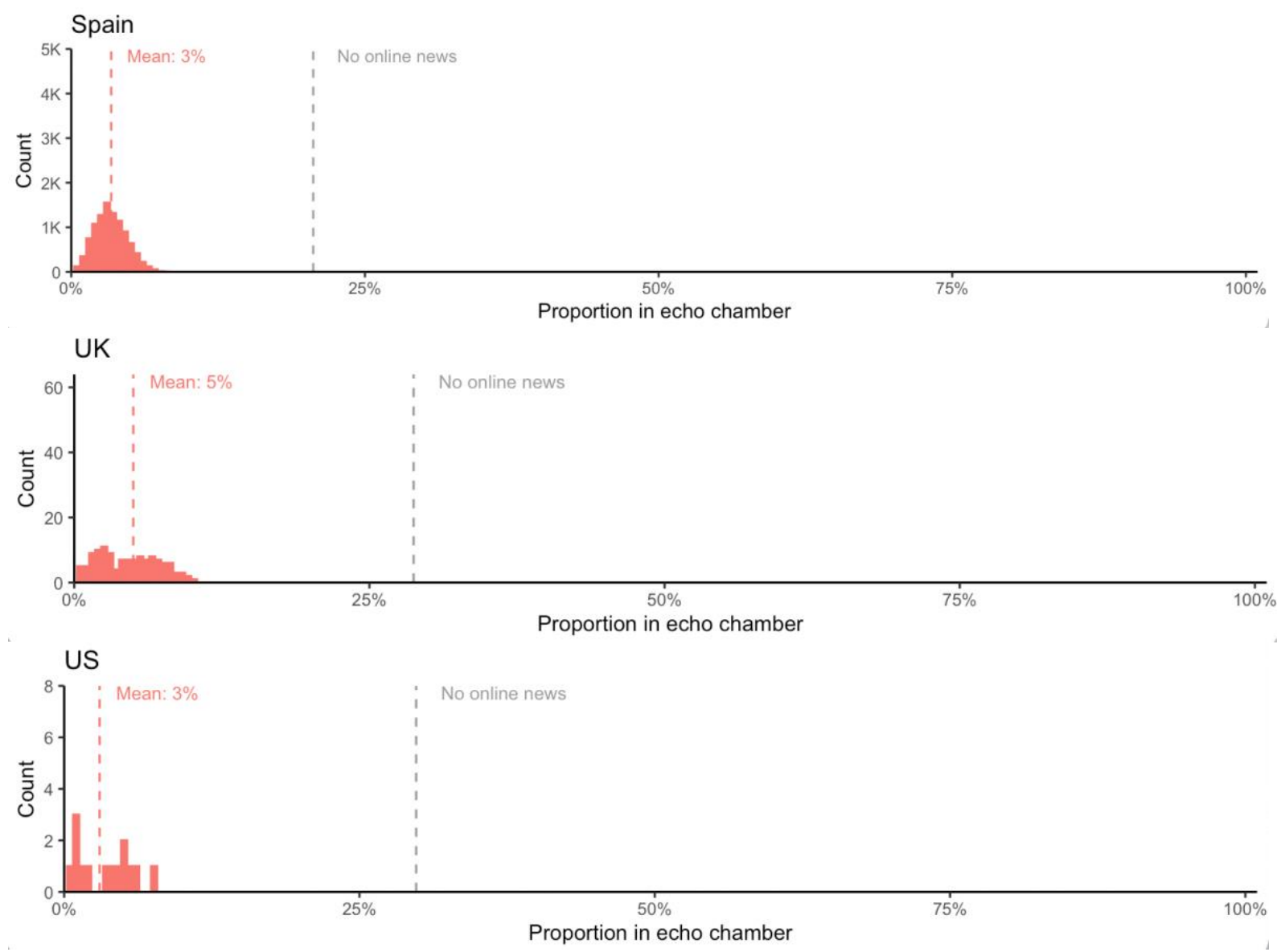

Figure 1. Histograms showing proportion in randomly specified right echo chambers.

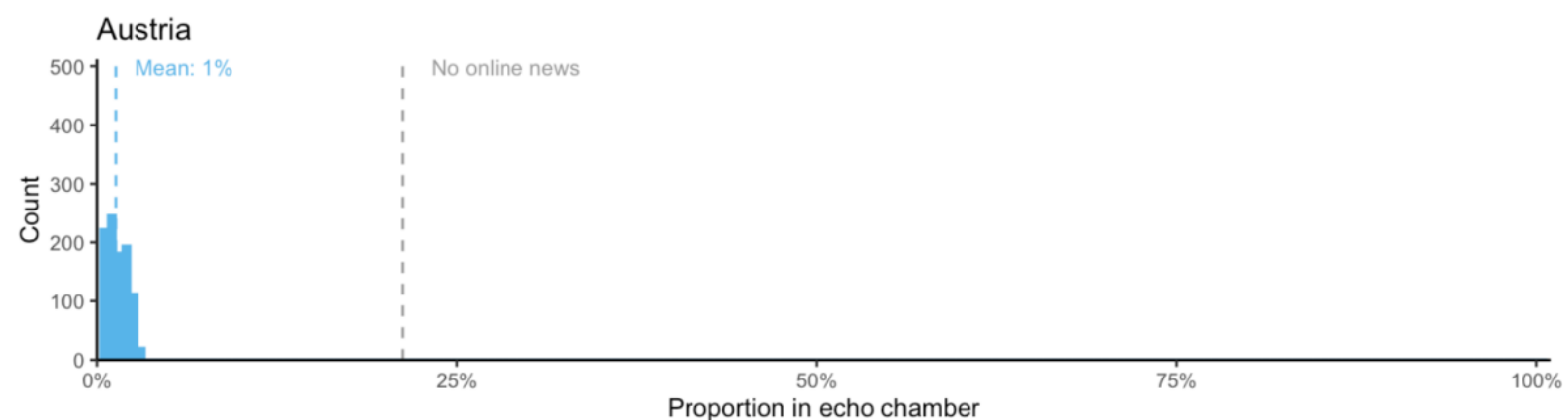


Fletcher, Robertson, Nielsen

Journal of Quantitative Description: Digital Media 1(2021) 20
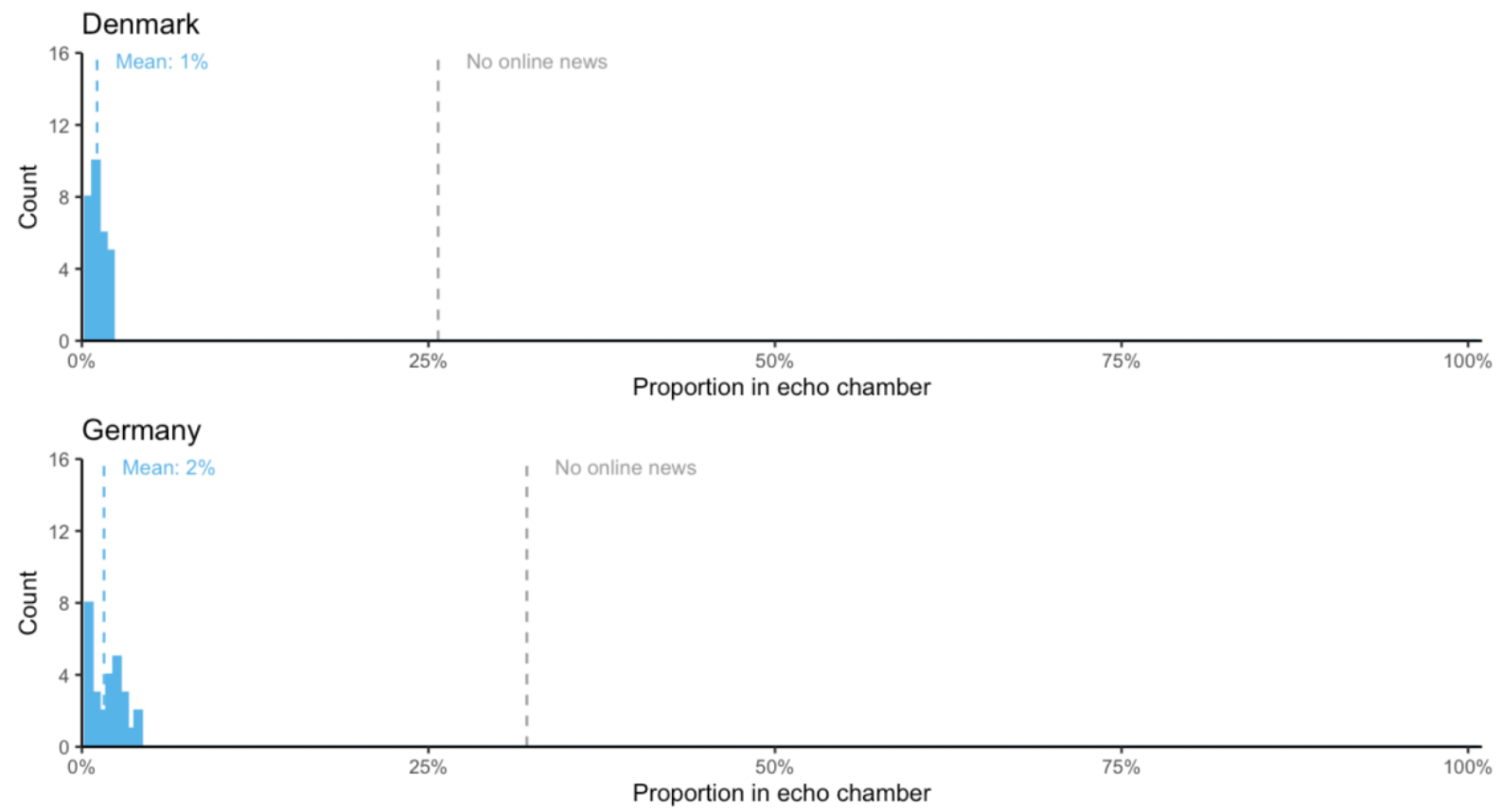

\section{Norway}

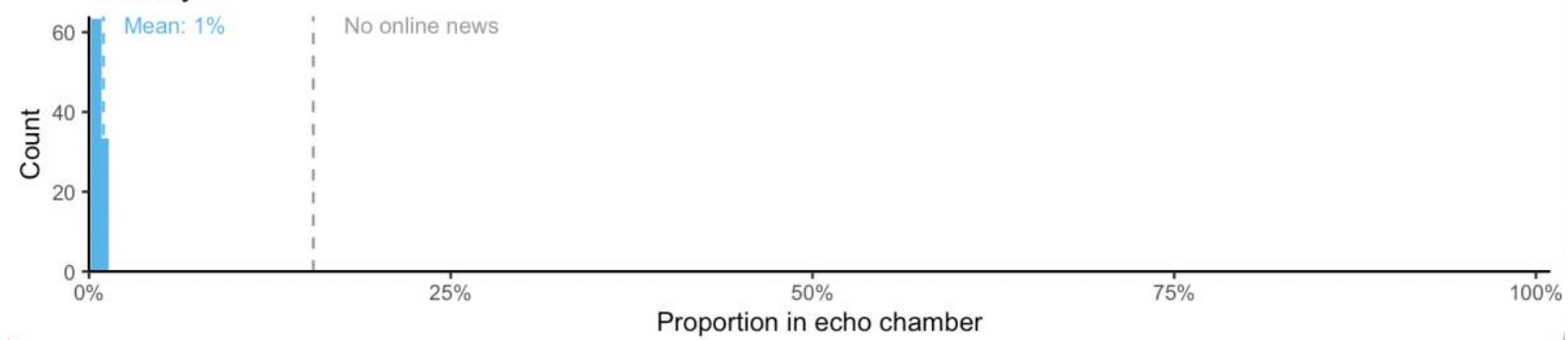

Spain

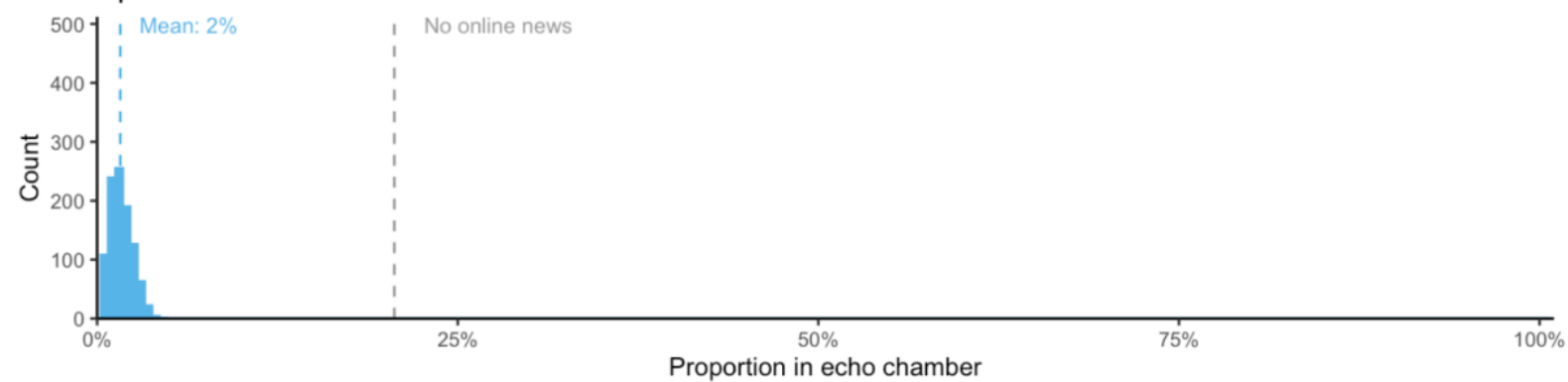



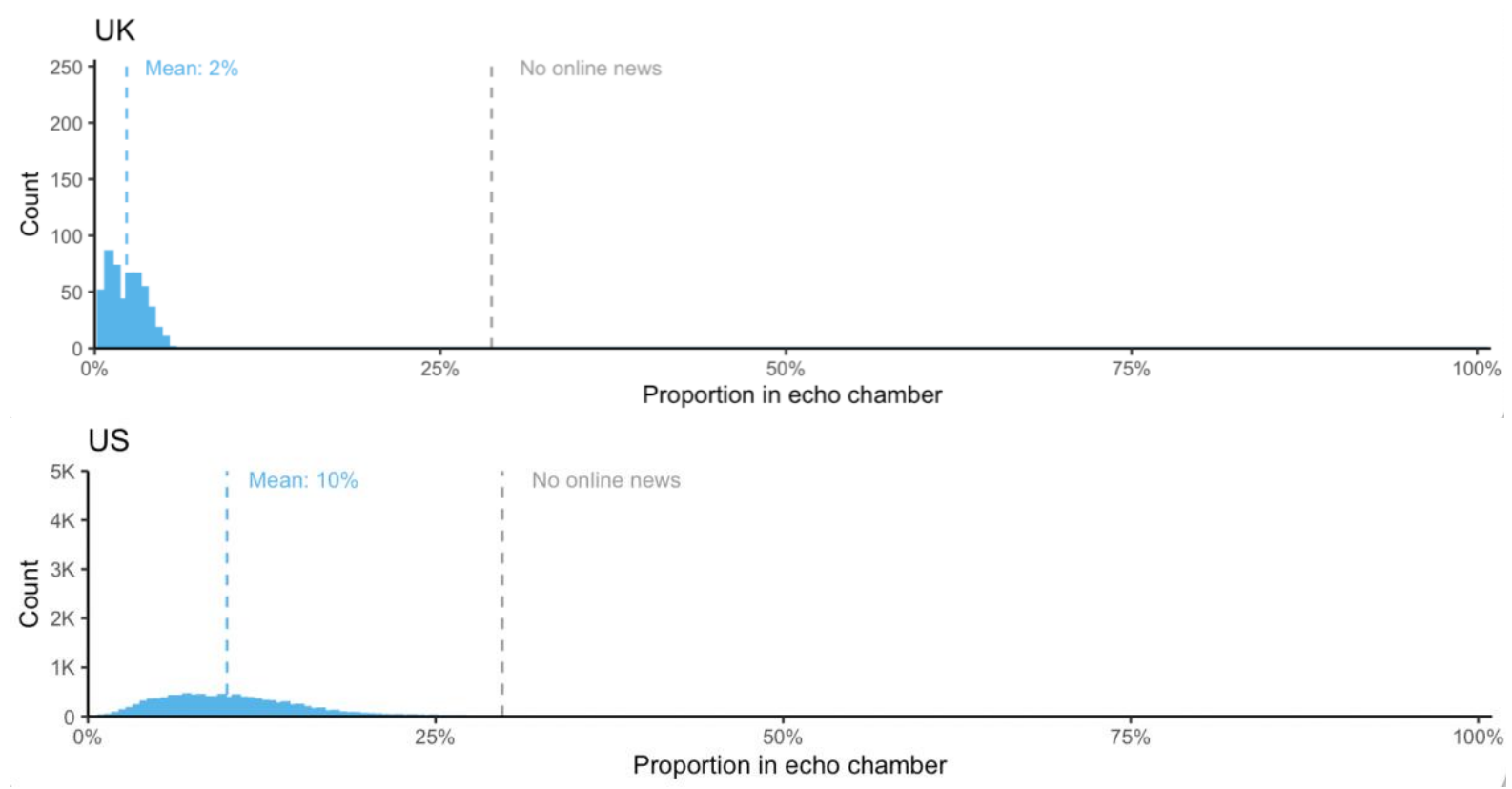

Figure 2. Histograms showing proportion in randomly specified left echo chambers.

Histograms showing the results across different specifications are displayed in Figures 1 and 2 (accompanying tables are in Section 1 of the Appendix). The results show that around $5 \%$ of the population are in either a left or right echo chamber in most countries. The one clear exception to this the US, where an average of $10 \%$ are in the left echo chamber, and $3 \%$ in the right echo chamber. The range of echo chamber sizes for different left or right specifications - which, of course, includes the specification producing the largest possible echo chamber-is usually between 0 and 10\%. Again, the main exception is the left echo chamber in the US (0-31\%).

We also see that the average size of left and right echo chambers is much smaller than the proportion who do not use online news at all in every country- the figure for which does not change, regardless of what outlets are counted as sufficiently left- or right- 
leaning. Moreover, none of the tens of thousands of specifications we analysed produced echo chambers larger than the proportion who do not use online news in any country.

These results are based excluding outlets in the range $(-0.05,0.05)$. Although we believe that this decision is theoretically justified - and, in fact, may already include too many non-partisan outlets - the values used as upper and lower limits are somewhat arbitrary. To explore the effect of relaxing this threshold we repeat the analysis for a range of different values - including 0 , where no outlets are excluded. The results are discussed in full in the Section 3 of the Appendix. They show that relaxing the threshold (inevitably) increases the average size of the right and left echo chambers - but the difference it makes is small. Setting the exclusion threshold to $(-0.02,0.02)$ has almost no effect. For the right echo chamber, setting the exclusion threshold from 0.05 to 0 increases the estimates from around $2 \%$ on average to around $7 \%$, while relaxing for the threshold for the left echo chamber increases the average from $3 \%$ to $7 \%$. In countries like Norway and the UKwhere the public broadcaster reaches a very large proportion of the population-lowering the threshold to 0 can increase the size of the echo chamber to $10-13 \%$. However, to reiterate again, we do not believe that including outlets in echo chamber estimates with audiences almost equally balanced between left and right, and which in some cases operate under a legal requirement to be impartial, is theoretically justified.

\section{Discussion}

In general, the results suggest that although decisions about what outlets constitute an echo chamber do make a difference to their estimated size, in most cases that difference is surprisingly small - even across countries with very different media systems and outlets that vary in terms of content and journalistic practices. They further suggest that even though some may have strong feelings about the slant of particular outlets, the direction and strength of that slant, and ultimately whether they constitute an echo chamber or notthese details become less important because of four basic facts: (i) news audiences in most countries show very high levels of overlap (Fletcher \& Nielsen, 2017), (ii) audiences tend 
to converge on large mainstream news outlets (Nelson \& Webster, 2017), (iii) a significant minority do not use online news at all (Flaxman et al., 2016), and (iv) the audiences for the most partisan sites are usually small (Newman et al., 2019). In many cases, this will preclude the existence of large partisan online news echo chambers on either the left or the right under most definitions.

Results are largely consistent across countries, but the US is an outlier because of the relatively large average size, and large range of estimates, for the echo chamber on the left. Whereas in most countries estimates of echo chamber size vary little as different outlets are excluded or excluded, for the left echo chamber in the US these decisions are more consequential. The audience-based method for determining outlet slant consistently identifies more left-leaning than right-leaning outlets in the US and finds that left-leaning outlets typically account for a larger share of news use (Guess, 2021; Pew Research Centre 2021). In short, if outlets with relatively large audiences (e.g., CNN and the New York Times) are included in echo chamber specifications, the size of the echo chamber will be relatively large, but if they are excluded, estimates shrink.

People will have different views on whether these outlets should be included or excluded. However, in thinking about the echo chamber on the left it is worth noting that the higher estimates are aligned with previous research finding that US liberals are less likely to seek out news from conservative outlets than vice versa (Eady et al., 2019). We also note that the boundary between left-leaning and right-leaning outlets is set using the average political leaning of the population, ensuring that outlets can only be classified as left-leaning if disproportionately large numbers of people who describe themselves as leftwing specifically (rather than center) choose to use them-and not because very rightleaning outlets somehow shift the mid-point. However, it is important to reiterate again that outlets are left-leaning (or right-leaning) in a relative rather than an absolute sensebecause what prompts people to identify as left- or right-leaning in the first place will be conditioned by the political context and their views about the other side. It is for this reason that outlets should not necessarily be seen as right- or left-leaning equivalents of one 
another (Benkler et al., 2018), and we largely avoid comparisons between outlets or echo chambers between countries or within countries between left and right.

Several further caveats should also be kept in mind. First, although we aimed to test every possible combination of outlets in the available data, the results still depend on what outlets were originally included in the survey. Because of practical limitations, we could only ask about the use of around 30 of the most popular online news outlets in each country. As such, we do not capture the full long (and thin) tail of news outlets available online. However, what we do capture, importantly, is the short (and large) head-and it is these outlets with large reach that have the most potential to influence the results. (As has been demonstrated elsewhere, a small number of news publishers account for most of the time people spend with online news, see e.g., Hindman, 2018) Therefore, we believe that the inclusion or exclusion of various smaller outlets would have almost no effect on the overall finding that only a small percentage are in online news echo chambers.

Second, the survey used specific measures of news use and political attitudes. The survey used a binary measure of whether the respondent had used a news outlet online in the last week and asked respondents to place themselves on a left-right scale. However, it is possible that different results would have emerged if the survey had used alternative measures, such as the frequency of news use or political party identification.

Third, and more generally, there are several limitations associated with using surveys to measure news use. Specifically, respondents can struggle to accurately recall their past media use, they may offer socially desirable responses that underestimate the use of more partisan or low-quality outlets, or they may engage in expressive responding that overestimates the use of outlets closely aligned with specific attitudes or identities. All of this means that survey responses may not accurately reflect the underlying reality of people's news use, or match data collected using different methodologies such as passive web tracking (Prior, 2007; Guess, 2015; Pew Research Center, 2020). These problems may have particularly pronounced consequences for the analysis here. For example, if people 
intentionally or unintentionally underestimate their use of more partisan news sources, this might artificially shrink estimates of echo chamber size.

To respond to some of these limitations, and to explore the robustness of our estimates, we apply the same analysis procedure to different data-collected for different purposes, using different methodologies, and employing different measures. Doing so may show which of the above limitations are most consequential. Although we are not aware of a dataset that contains the required measures across all the countries analysed here, Wave 57 of the American Trends Panel survey (Pew, 2021) offers a US comparison, and the web tracking dataset used in Kalogeropoulos et al. (2019) provides one for the UK. The comparison with the US Pew data is useful because, although it was collected just a few months earlier than the data analysed here, it asks about the use of different outlets and uses different measures of news use and political attitudes. The UK data offers a useful comparison because it is based on desktop web tracking from YouGov Pulse, and although it is several years older than the data analysed here, it tracks the use of a very similar set of outlets without relying on recall.

The results of this additional analysis are described in more detail in Section 4 of the Appendix, but to summarise here, applying the same procedure produced very similar estimates of echo chamber size in both the US and the UK. The Pew dataset produced an average echo chamber estimate of $3 \%$ on the right and $7 \%$ for the left (compared to $3 \%$ and $10 \%$, respectively), and the UK tracking data produced an average echo chamber estimate of $3 \%$ for the left and $5 \%$ on the right (compared to $2 \%$ and $5 \%$ ). This suggests that the results we present here are not highly sensitive to differences in measures of news use and political attitudes, outlets included, and methods of data collection. However, it is also important to acknowledge that these two comparisons alone certainly do not allow us to conclude that the data and the approach is robust to all such differences. 


\section{Conclusion}

Previous work has shown that although people do engage in partisan selective exposure (e.g., Iyengar \& Hahn, 2009), they do not necessarily engage in selective avoidance (e.g., Garrett, 2009; 2013). However, few studies have built on these findings to estimate the size of online echo chambers, and fewer still have done so in a comparable way across different countries. In this paper, we have used data from an online survey of news users to estimate the proportion of people who live in left-right partisan online news echo chambers in seven different countries. By estimating the average size of echo chambers using different combinations of outlets with partisan audiences, we find that in almost all countries covered, only a minority of approximately $5 \%$ of internet users inhabit them, and in every country covered, more internet users consume no online news at all than occupy partisan online echo chambers. Furthermore, in most cases we find that decisions over whether to include or exclude particular news outlets make little difference to echo chamber estimates. The clearest exception is the left-leaning online news echo chamber in the US, where decisions about whether to include outlets with strongly left-leaning audiences can move estimated size anywhere between 0 and around $30 \%$ of the population.

This analysis provides us with a basic descriptive, empirical understanding of the prevalence of political echo chambers online, a substantively important and frequently discussed issue. Our paper also provides a framework for examining the prevalence of echo chambers across countries and how they wax or wane over time-though as stressed throughout, any comparison between different echo chambers needs to avoid false

equivalence between echo chambers of different sorts that are often substantially quite different, both within countries and between countries. The fact that the left echo chamber in the US is potentially larger than the echo chamber on the right (depending on how we specify each) does not mean we should be more concerned about it. It is only through the analysis of content that we can arrive at such judgements. 
For many of the same reasons we do not examine cross-cutting exposure. The approach developed here could provide the basis for estimating cross-cutting exposure by considering the partisan leanings of those who occupy the echo chambers. Similarly, it could be used to identify differences between echo chambers consisting of low new users who rely on a single partisan source versus the very different echo chambers occupied by heavy news users relying on a multiplicity of partisan sources with a similar orientation.

The results presented here further document that online news echo chambers are real, but also that only a small minority of online news users occupy them-because the vast majority in every country covered use several different sources of news with different orientations. Even in the US, where we find a larger minority occupying partisan online news echo chambers than in other countries, it is still a minority nonetheless. Benchmarking the prevalence of echo chambers against the percentage of respondents who say they have used no online news at all in the last week also highlights that this is a far larger group. Limited or no online news use is demonstrably a more common phenomenon than online echo chambers, even among internet users with easy access to a great abundance of different sources. Of course, concerns over news inequalities and online news echo chambers are to some extent separate, and contemporary media environments can have more than one problem at the same time. But the fact that so much energy and attention is devoted to echo chambers and so little to news inequalities should give us pause.

\section{Funding}

This research was supported by Google UK as part of the Google News Initiative. 


\section{References}

Bail, C. A., Argyle, L. P., Brown, T. W., Bumpus, J. P., Chen, H., Fallin Hunzaker, M. B., Lee, J., Mann, M., Merhout, F., \& Volfovsky, A. (2018). Exposure to Opposing Views on Social Media Can Increase Political Polarization. Proceedings of the National Academy of Sciences in the United States of America, 115(37), 9216-9221. https://doi.org/10.1073/pnas.1804840115

Bakshy, E., Messing, S., \& Adamic, L. A. (2015). Exposure to ideologically diverse news and opinion on Facebook. Science, 348, 1130-1132. https://doi.org/10.1126/science.aaa1160

Barberá, P., Jost, J. T., Nagler, J., Tucker, J. A., \& Bonneau, R. (2015). Tweeting From Left to Right: Is Online Political Communication More Than an Echo Chamber? Psychological Science, 26(10), 1531-1542. https://doi.org/10.1177/0956797615594620

Benkler, Y., Faris, R., \& Roberts, H. (2018). Network propaganda: Manipulation, disinformation, and radicalization in American politics. New York, NY: Oxford University Press.

Bennett, W. L., Lawrence, R. G., \& Livingston, S. (2008). When the Press Fails: Political Power and the News Media from Iraq to Katrina. Chicago, IL: University of Chicago Press.

Bos, L., Kruikemeier, S., \& de Vreese, C. (2016). Nation Binding: How Public Service Broadcasting Mitigates Political Selective Exposure. PLOS ONE, 11(5), 1-11. https://doi.org/10.1371/journal.pone.0155112

Boulianne, S., Koc-Michalska, K., \& Bimber, B. (2020). Right-wing populism, social media and echo chambers in Western democracies. New Media \& Society, 22(4), 683-699. https://doi.org/10.1177/1461444819893983 
JQD:DM 1(2021)

Online News Echo Chambers 29

Bruns, A. (2019). Are Filter Bubbles Real? Cambridge, UK: Polity Press.

Cardenal, A. S., Aguilar-Paredes, C., Cristancho, C., \& Majó-Vázquez, S. (2019). Echochambers in online news consumption: Evidence from survey and navigation data in Spain. European Journal of Communication, 34(4), 360-376. https://doi.org/10.1177/0267323119844409

Castro-Herrero, L., Nir, L., \& Skovsgaard, M. (2018). Bridging Gaps in Cross-Cutting Media Exposure: The Role of Public Service Broadcasting. Political Communication, 35(4), 542-565. https://doi.org/10.1080/10584609.2018.1476424

Chen, H.-T., Guo, L., \& Su, C. C. (2020). Network Agenda Setting, Partisan Selective Exposure, and Opinion Repertoire: The Effects of Pro- and Counter-Attitudinal Media in Hong Kong. Journal of Communication, 70(1), 35-59. https://doi.org/10.1093/joc/jqz042

Dahlgren, P. M. (2019). Selective Exposure to Public Service News over Thirty Years: The Role of Ideological Leaning, Party Support, and Political Interest. The International Journal of Press/Politics, 24(3), 293-314. https://doi.org/10.1177/1940161219836223

Dahlgren, P. M., Shehata, A., \& Strömbäck, J. (2019). Reinforcing spirals at work? Mutual influences between selective news exposure and ideological leaning. European Journal of Communication, 34(2), 159-174. https://doi.org/10.1177/0267323119830056

Del Vicario, M., Vivaldo, G., Bessi, A., Zollo, F., Scala, A., Caldarelli, G., \& Quattrociocchi, W. (2016). Echo Chambers: Emotional Contagion and Group Polarization on Facebook. Scientific Reports, 6(1), 1-12. https://doi.org/10.1038/srep37825

Dubois, E., \& Blank, G. (2018). The echo chamber is overstated: The moderating effect of political interest and diverse media. Information, Communication \& Society, 


\section{1(5), 729-745. https://doi.org/10.1080/1369118X.2018.1428656}

Dvir-Gvirsman, S., Tsfati, Y., \& Menchen-Trevino, E. (2016). The extent and nature of ideological selective exposure online: Combining survey responses with actual web log data from the 2013 Israeli Elections. New Media \& Society, 18(5), 857877. https://doi.org/10.1177/1461444814549041

Eady, G., Nagler, J., Guess, A., Zilinsky, J., \& Tucker, J. A. (2019). How Many People Live in Political Bubbles on Social Media? Evidence From Linked Survey and Twitter Data. SAGE Open, 9(1), 1-21. https://doi.org/10.1177/2158244019832705

Flaxman, S., Goel, S., \& Rao, J. M. (2016). Filter Bubbles, Echo Chambers, and Online News Consumption. Public Opinion Quarterly, 80(S1), 298-320. https://doi.org/10.1093/poq/nfw006

Fletcher, R., Cornia, A., \& Nielsen, R. K. (2020). How Polarized Are Online and Offline News Audiences? A Comparative Analysis of Twelve Countries. The International Journal of Press/Politics, 25(2), 169-195. https://doi.org/10.1177/1940161219892768

Fletcher, R., Kalogeropoulos, A., \& Nielsen, R. K. (2021). More Diverse, More Politically Varied: How Social Media, Search Engines and Aggregators Shape News Repertoires in the United Kingdom. New Media \& Society, Online First. https://doi.org/10.1177/14614448211027393

Fletcher, R., Newman, N., \& Schulz, A. (2020). A Mile Wide, An Inch Deep: Online News and Media Use in the 2019 UK General Election. Oxford, UK: Reuters Institute for the Study of Journalism.

Fletcher, R., \& Nielsen, R. K. (2017). Are News Audiences Increasingly Fragmented? A Cross-National Comparative Analysis of Cross-Platform News Audience Fragmentation and Duplication: Are News Audiences Increasingly Fragmented? 
JQD:DM 1(2021)

Online News Echo Chambers 31

Journal of Communication, 67(4), 476-498. https://doi.org/10.1111/jcom.12315

Fletcher, R., \& Nielsen, R. K. (2018a). Are People Incidentally Exposed to News on Social Media? A Comparative Analysis. New Media \& Society, 20(7), 24502468. https://doi.org/10.1177/1461444817724170

Fletcher, R., \& Nielsen, R. K. (2018b). Automated Serendipity: The Effect of Using Search Engines on the Diversity and Balance of News Repertoires. Digital Journalism, 8(6), 976-989. https://doi.org/10.1080/21670811.2018.1502045

Garrett, R. K. (2009). Echo chambers online? Politically motivated selective exposure among Internet news users. Journal of Computer-Mediated Communication, 14(2), 265-285. https://doi.org/10.1111/j.1083-6101.2009.01440.x

Garrett, R. K. (2013). Selective Exposure: New Methods and New Directions. Communication Methods and Measures, 7(3-4), 247-256. https://doi.org/10.1080/19312458.2013.835796

Garrett, R. K., Carnahan, D., \& Lynch, E. K. (2013). A Turn Toward Avoidance? Selective Exposure to Online Political Information, 2004-2008. Political Behavior, 35(1), 113-134. https://doi.org/10.1007/s11109-011-9185-6

Garrett, R. K., \& Stroud, N. J. (2014). Partisan Paths to Exposure Diversity: Differences in Pro- and Counterattitudinal News Consumption. Journal of Communication, 64(4), 680-701. https://doi.org/10.1111/jcom.12105

Gentzkow, M., \& Shapiro, J. M. (2011). Ideological Segregation Online and Offline. The Quarterly Journal of Economics, 126(4), 1799-1839. https://doi.org/10.1093/qje/qjr044

Guess, A. M. (2015). Measure for Measure: An Experimental Test of Online Political Media Exposure. Political Analysis, 23(1), 59-75. https://doi.org/10.1093/pan/mpu010 
Guess, A. M. (2021). (Almost) Everything in Moderation: New Evidence on American's Online Media Diets. American Journal of Political Science, 1-16. Advance online publication. https://doi.org/10.1111/ajps.12589

Hallin, D. C., \& Mancini, P. (2004). Comparing Media Systems: Three Models of Media and Politics. Cambridge, UK: Cambridge University Press.

Hameleers, M., Bos, L., \& de Vreese, C. H. (2018). Selective Exposure to Populist Communication: How Attitudinal Congruence Drives the Effects of Populist Attributions of Blame. Journal of Communication, 68(1), 51-74. https://doi.org/10.1093/joc/jqx001

Hindman, M. (2018). The Internet Trap: How the Digital Economy Builds Monopolies and Undermines Democracy. Princeton, NJ: Princeton University Press.

Holt, K., Ustad Figenschou, T., \& Frischlich, L. (2019). Key Dimensions of Alternative News Media. Digital Journalism, 7(7), 860-869. https://doi.org/10.1080/21670811.2019.1625715

Iyengar, S., \& Hahn, K. S. (2009). Red Media, Blue Media: Evidence of Ideological Selectivity in Media Use. Journal of Communication, 59(1), 19-39. https://doi.org/10.1111/j.1460-2466.2008.01402.x

Jackson, S. J., Bailey, M., \& Welles, B. F. (2020). \#HashtagActivism: Networks of Race and Gender Justice. Cambridge, MA: The MIT Press.

Jamieson, K. H., \& Cappella, J. N. (2008). Echo chamber: Rush Limbaugh and the conservative media establishment. New York, NY: Oxford University Press.

Johnson, T., Kulesa, P., Cho, Y. I., \& Shavitt, S. (2005). The Relation Between Culture and Response Styles: Evidence from 19 Countries. Journal of Cross-Cultural Psychology, 36(2), 264-77. https://doi.org/10.1177/0022022104272905 
Johnson, T. J., Zhang, W., \& Bichard, S. L. (2011). Voices of Convergence or Conflict? A Path Analysis Investigation of Selective Exposure to Political Websites. Social Science Computer Review, 29(4), 449-469. https://doi.org/10.1177/0894439310379962

Kim, M., \& Lu, Y. (2020). Testing Partisan Selective Exposure in a Multidimensional Choice Context: Evidence from a Conjoint Experiment. Mass Communication and Society, 23(1), 107-127. https://doi.org/10.1080/15205436.2019.1636283

Kim, Y. (2015). Does Disagreement Mitigate Polarization? How Selective Exposure and Disagreement Affect Political Polarization. Journalism \& Mass Communication Quarterly, 92(4), 915-937. https://doi.org/10.1177/1077699015596328

Kreiss, D. (2017). The fragmenting of the civil sphere: How partisan identity shapes the moral evaluation of candidates and epistemology. American Journal of Cultural Sociology, 5(3), 443-459. https://doi.org/10.1057/s41290-017-0039-5

Lawrence, E., Sides, J., \& Farrell, H. (2010). Self-Segregation or Deliberation? Blog Readership, Participation, and Polarization in American Politics. Perspectives on Politics, 8(1), 141-157. https://doi.org/10.1017/S1537592709992714

Masip, P., Suau, J., \& Ruiz-Caballero, C. (2020). Incidental Exposure to Non-LikeMinded News through Social Media: Opposing Voices in Echo-Chambers' News Feeds. Media and Communication, 8(4), 53-62. https://doi.org/10.17645/mac.v8i4.3146

McPherson, M., Smith-Lovin, L., \& Cook, J. M. (2001). Birds of a Feather: Homophily in Social Networks. Annual Review of Sociology, 27(1), 415-444. https://doi.org/10.1146/annurev.soc.27.1.415

Messing, S., \& Westwood, S. J. (2014). Selective Exposure in the Age of Social Media: Endorsements Trump Partisan Source Affiliation When Selecting News Online. 
Communication Research, 41(8), 1042-1063. https://doi.org/10.1177/0093650212466406

Metzger, M. J., Hartsell, E. H., \& Flanagin, A. J. (2020). Cognitive Dissonance or Credibility? A Comparison of Two Theoretical Explanations for Selective Exposure to Partisan News. Communication Research, 47(1), 3-28. https://doi.org/10.1177/0093650215613136

Mutz, D. C. (2006). Hearing the Other Side: Deliberative Versus Participatory Democracy. Cambridge, UK: Cambridge University Press. https://doi.org/10.1017/CBO9780511617201

Nelson, J. L., \& Webster, J. G. (2017). The Myth of Partisan Selective Exposure: A Portrait of the Online Political News Audience. Social Media + Society, 3(3), 113. https://doi.org/10.1177/2056305117729314

Newman, N., Fletcher, R., Kalogeropoulos, A., \& Nielsen, R. K. (2019). Reuters Institute Digital News Report 2019. Oxford, UK: Reuters Institute for the Study of Journalism.

Newman, N., Fletcher, R., Schulz, A., And1, S., \& Nielsen, R. K. (2020). Reuters Institute Digital News Report 2020. Oxford, UK: Reuters Institute for the Study of Journalism.

Pariser, E. (2011). The filter bubble: What the Internet is hiding from you. London, UK: Viking.

Pew Research Center. (2014). Political Polarization \& Media Habits. Pew Research Center. https://www.journalism.org/2014/10/21/political-polarization-mediahabits/

Pew Research Center. (2020). Measuring News Consumption in a Digital Era. Pew Research Center. https://www.journalism.org/2020/12/08/measuring-news- 
JQD:DM 1(2021)

consumption-in-a-digital-era/

Pew Research Center. (2021). How Americans Navigated the News in 2020: A

Tumultuous Year in Review. Pew Research Center.

https://www.journalism.org/2021/02/22/how-americans-navigated-the-news-in2020-a-tumultuous-year-in-review/

Prior, M. (2009). The Immensely Inflated News Audience: Assessing Bias in SelfReported News Exposure. Public Opinion Quarterly, 73, 130-143. https://doi.org/10.1093/poq/nfp002

Prior, M. (2013). Media and Political Polarization. Annual Review of Political Science, 16(1), 101-127. https://doi.org/10.1146/annurev-polisci-100711-135242

Scharkow, M., Mangold, F., Stier, S., \& Breuer, J. (2020). How Social Network Sites and Other Online Intermediaries Increase Exposure to News. Proceedings of the National Academy of Sciences in the United States of America, 117(6), 27612763. https://doi.org/10.1073/pnas.1918279117

Sears, D. O., \& Freedman, J. L. (1967). Selective Exposure to Information: A Critical Review. Public Opinion Quarterly, 31(2), 194-213. https://doi.org/10.1086/267513

Simonsohn, U., Simmons, J. P., \& Nelson, L. D. (2015). Specification Curve: Descriptive and Inferential Statistics on All Reasonable Specifications. SSRN Electronic Journal. https://doi.org/10.2139/ssrn.2694998

Singer, J. B. (2005). The political j-blogger: 'Normalizing' a new media form to fit old norms and practices. Journalism, 6(2), 173-198. https://doi.org/10.1177/1464884905051009

Skovsgaard, M., Shehata, A., \& Strömbäck, J. (2016). Opportunity Structures for Selective Exposure: Investigating Selective Exposure and Learning in Swedish 
Election Campaigns Using Panel Survey Data. The International Journal of Press/Politics, 21(4), 527-546. https://doi.org/10.1177/1940161216658157

Stroud, N. J. (2011). Niche news: The politics of news choice. Oxford, UK: Oxford University Press.

Sunstein, C. R. (2017). \#Republic: Divided Democracy in the Age of Social Media. Princeton, NJ: Princeton University Press.

Trilling, D., \& Schoenbach, K. (2015). Challenging Selective Exposure: Do online news users choose sites that match their interests and preferences? Digital Journalism, 3(2), 140-157. https://doi.org/10.1080/21670811.2014.899749

Tucker, J. A., Guess, A., Barbera, P., Vaccari, C., Siegel, A., Sanovich, S., Stukal, D., \& Nyhan, B. (2018). Social Media, Political Polarization, and Political Disinformation: A Review of the Scientific Literature. Hewlett Foundation. https://hewlett.org/wp-content/uploads/2018/03/Social-Media-PoliticalPolarization-and-Political-Disinformation-Literature-Review.pdf

Van Aelst, P., Strömbäck, J., Aalberg, T., Esser, F., de Vreese, C., Matthes, J., Hopmann, D., Salgado, S., Hubé, N., Stępińska, A., Papathanassopoulos, S., Berganza, R., Legnante, G., Reinemann, C., Sheafer, T., \& Stanyer, J. (2017). Political communication in a high-choice media environment: A challenge for democracy? Annals of the International Communication Association, 41(1), 3-27. https://doi.org/10.1080/23808985.2017.1288551

van Kempen, H. (2007). Media-Party Parallelism and Its Effects: A Cross-National Comparative Study. Political Communication, 24(3), 303-320. https://doi.org/10.1080/10584600701471674

Webster, J. G., \& Ksiazek, T. B. (2012). The Dynamics of Audience Fragmentation: Public Attention in an Age of Digital Media. Journal of Communication, 62(1), 39-56. https://doi.org/10.1111/j.1460-2466.2011.01616.x 
JQD:DM 1(2021)

Online News Echo Chambers 37

Weeks, B. E., Ksiazek, T. B., \& Holbert, R. L. (2016). Partisan Enclaves or Shared Media Experiences? A Network Approach to Understanding Citizens' Political News Environments. Journal of Broadcasting \& Electronic Media, 60(2), 248268. https://doi.org/10.1080/08838151.2016.1164170

Wicks, R. H., Wicks, J. L., \& Morimoto, S. A. (2014). Partisan Media Selective Exposure During the 2012 Presidential Election. American Behavioral Scientist, 58(9), 1131-1143. https://doi.org/10.1177/0002764213506208

Williams, H. T. P., McMurray, J. R., Kurz, T., \& Hugo Lambert, F. (2015). Network analysis reveals open forums and echo chambers in social media discussions of climate change. Global Environmental Change, 32, 126-138. https://doi.org/10.1016/j.gloenvcha.2015.03.006

Yang, T., Majó-Vázquez, S., Nielsen, R. K., \& González-Bailón, S. (2020). Exposure to news grows less fragmented with an increase in mobile access. Proceedings of the National Academy of Sciences, 117(46), 28678-28683. https://doi.org/10.1073/pnas.2006089117

Zuiderveen Borgesius, F. J., Trilling, D., Möller, J., Bodó, B., de Vreese, C. H., \& Helberger, N. (2016). Should We Worry about Filter Bubbles? Internet Policy Review, 5(1), 1-16. https://doi.org/10.14763/2016.1.401 


\section{Appendix}

1. Proportion in randomly specified echo chambers

2. Estimating outlet slant

3. Exploring different exclusion thresholds

4. Exploring different datasets

5. List of outlets analysed

\section{Proportion in randomly specified echo chambers}

The tables in this section show the same results as the histograms in Figures 1 and 2 in the main text. We show only integers to avoid spurious precision.

Table A1. Proportion in randomly specified right echo chambers.

\begin{tabular}{cccc}
\hline Country & Mean $(\%)$ & Range $(\%)$ & No online news $(\%)$ \\
\hline Austria & 2 & $0-4$ & 21 \\
Denmark & 1 & $0-2$ & 26 \\
Germany & 3 & $0-6$ & 32 \\
Norway & 1 & $0-3$ & 16 \\
Spain & 3 & $0-9$ & 21 \\
UK & 5 & $0-10$ & 29 \\
US & 3 & $0-8$ & 30 \\
\hline
\end{tabular}

Table A2. Proportion in randomly specified left echo chambers.

\begin{tabular}{cccc}
\hline Country & Mean $(\%)$ & Range $(\%)$ & No online news $(\%)$ \\
\hline Austria & 1 & $0-3$ & 21 \\
Denmark & 1 & $0-2$ & 26 \\
Germany & 2 & $0-4$ & 32
\end{tabular}




\begin{tabular}{cccc} 
Norway & 1 & $0-1$ & 16 \\
Spain & 2 & $0-4$ & 21 \\
UK & 2 & $0-6$ & 29 \\
US & 10 & $0-31$ & 30 \\
\hline
\end{tabular}

\section{Estimating Outlet Slant}

The audience-based method of estimating outlet slant (Gentzkow \& Shapiro, 2011) tends to produce consistent results, even with different data and methods. To demonstrate this, we compare estimates from Bakshy et al. (2015) and the Pew Research Center (2021) with those from the data analysed in the main text.

The Pew (2021) estimates are based on data they collected from Wave 57 of their American Trends Panel in November 2019 but are computed by the authors using the approach described in the main text. However, the Pew survey differs from the survey here in two main ways. First, it asked respondents about their use of 30 news outlets for "political and election news" as opposed to news generally. Second, it did not ask about left-right leaning, but rather "In politics today, do you consider yourself a:" (-0.5) Democrat, (0.5) Republican, (0) Independent, (0) Something else, (NA) Refuse to answer (recoding is ours). Despite these differences, and possible ambiguities around how to code party affiliation, the estimates of outlet slant are very strongly correlated $(r=.98)$ (see panel 1, Figure A1).

The Bakshy et al. (2015) estimates come from observational data collected by Facebook and are computed using a different formula to the one used here (essentially the difference between use by Republicans and use by Democrats). Nonetheless, the estimates are again very strongly correlated with the data analysed in the main text $(r=.93)$ (panel 2, Figure A1). 


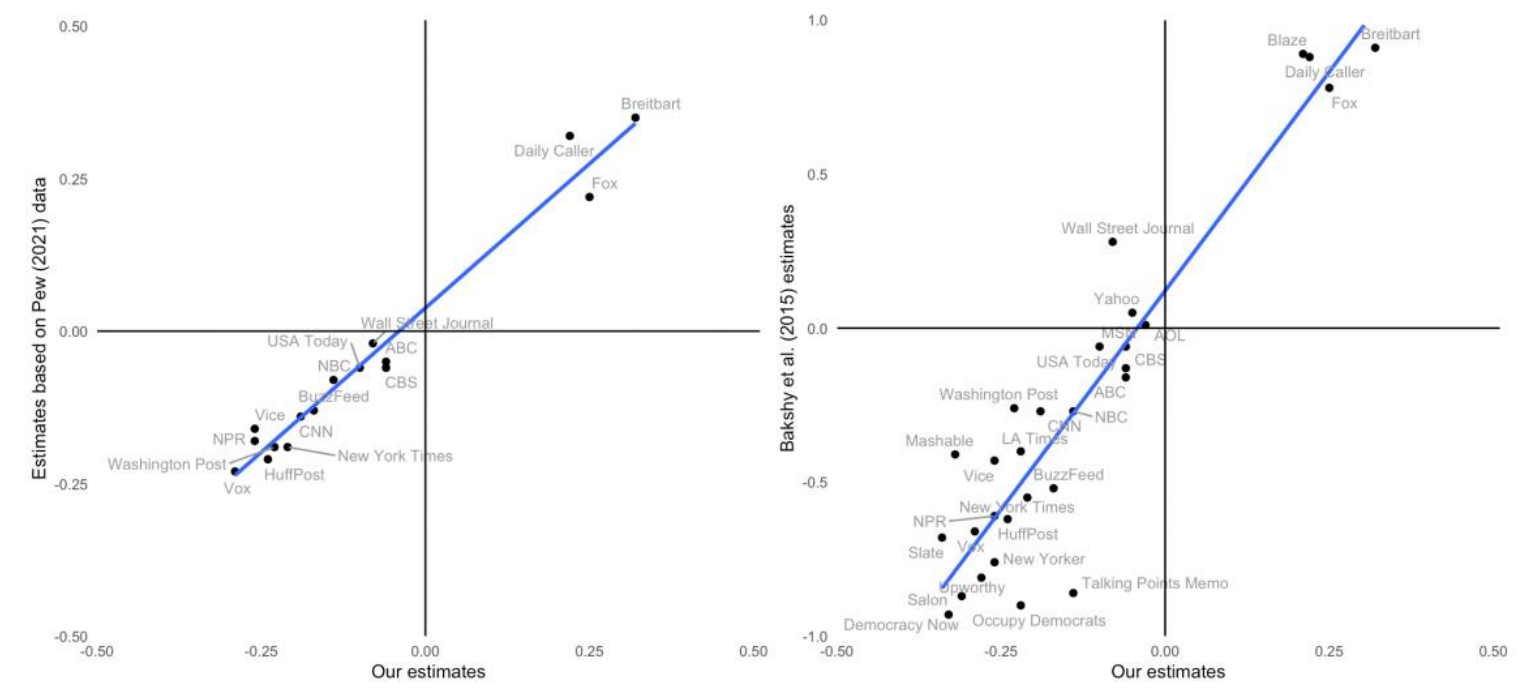

Figure A1. Different outlet slant estimates plotted against our estimates.

In both comparisons the scores do differ slightly, but almost all outlets are placed at the same end of the left-right spectrum - which means that it is unlikely that any of the more partisan outlets in the US have been mischaracterised. However, it remains largely unclear how reliable this approach is for countries which have less polarized patterns of media use than the US (Fletcher et al., 2020).

\section{Exploring Different Exclusion Thresholds}

In the main analysis we exclude outlets with very low absolute slant scores within the range (-.05 to .05). Outlets within this range- such as Yahoo! News in the US, and the $\mathrm{BBC}$ in the UK-have mixed and/or centrist audiences, meaning that the content they produce is unlikely to be strongly slanted towards either the left or the right.

We argue that including them in echo chamber specifications cannot be theoretically justified for the main analysis. However, in this section, we explore the difference that including them would make to the results. To do this, we aim to produce estimates of average echo chamber size for all possible specifications (that is to say, 
combinations of outlets), but with different exclusion thresholds. We also include an exclusion threshold of 0 , which means that all outlets with either a very slight left-leaning or right-leaning audience are included — and effectively turning what would otherwise be a trichotomy (left-leaning, no slant, right-leaning) to a dichotomy (left-leaning, rightleaning). In situations where there are more than 1024 possible specifications, 1000 specifications are drawn at random and the mean echo chamber size is computed from these only.

The results are displayed in Figure A2. Lowering the threshold from $(-0.05,0.05)$ to $(-0.02,0.02)$ makes very little difference in almost all cases. For the right echo chamber, lowering the exclusion threshold from 0.05 to 0 increases the estimates from around $2 \%$ on average to around $7 \%$. The increase is particularly large in Germany $(+8)$, where lowering the threshold allows popular web aggregators like t-online, GMX and Web.de to appear in specifications, and the UK $(+10)$ where lowering the threshold includes the BBC - which a significant minority use as their only online news source. For the left echo chamber, relaxing the threshold to 0 increases the estimates from around 3\% on average to around 7\%. The biggest increase is in Norway (+9) because NRK (public broadcaster) and VG (popular tabloid) can appear in specifications. 

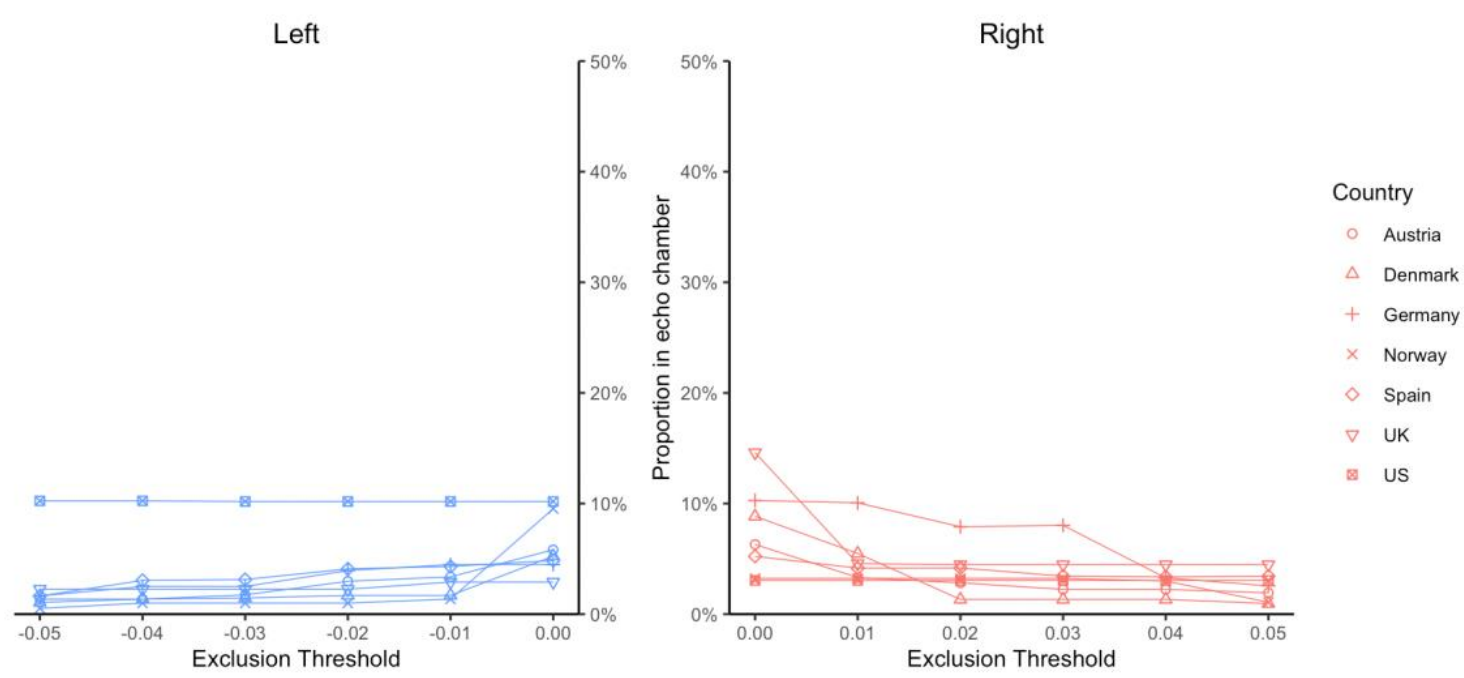

Figure A2. Average echo chamber estimates for different exclusion thresholds.

\section{Exploring Different Datasets}

Although Specification-Curve Analysis (Simonsohn et al., 2015) was used to address limitations with researcher degrees of freedom concerning which outlets qualify as sufficiently left or right leaning to constitute an echo chamber, parts of the data collection and analysis are still based on a series of somewhat arbitrary decisions that could have influenced the generalisability of the results and their interpretation. These include (but are not necessarily limited to):

1. Outlets in survey: How different would the results be if a different set of outlets were included in the survey?

2. Politics measure: How different would the results be if outlets were grouped using a different measure of political attitudes?

3. News use measure: How different would the results be using a different measure of news use?

4. Data collection: How different would the results be if tracking data was used? 
One way of partially answering these questions is to apply the same analysis to different datasets assembled in different ways, for different purposes, and containing different variables. This will provide a basic indication of how much difference changing certain variable or processes will make. We are not aware of a single dataset that contains the required variables on outlet-level online media use and political leaning, covering all the countries included here. However, Wave 57 of the American Trends Panel survey can provide this data for the US (Pew Research Center, 2021), and the web tracking dataset used in Kalogeropoulos et al. (2019) can provide it for the UK.

\section{US}

Table A3 compares Wave 57 of the American Trends Panel to the dataset used in the main analysis. It shows that although the fieldwork dates are only a few months apart, the mode, sample sizes - and most importantly - the measures of news use and political attitudes are all substantially different.

Table A3. Key differences between US datasets.

\begin{tabular}{|c|c|c|}
\hline & Data & $\begin{array}{l}\text { Pew American Trends } \\
\text { Panel survey (W57) }\end{array}$ \\
\hline Fieldwork dates & Jan/Feb 2020 & Oct/Nov 2019 \\
\hline Mode & $\begin{array}{l}\text { Non-probability online } \\
\text { panel }\end{array}$ & Probability online panel \\
\hline Sample size & 2,055 & 12,043 \\
\hline Outlets & 33 & 30 \\
\hline News use measure & $\begin{array}{l}\text { Online news use in the last } \\
\text { week }\end{array}$ & $\begin{array}{l}\text { Any politics and election } \\
\text { news use in the last week }\end{array}$ \\
\hline $\begin{array}{l}\text { Measure of political } \\
\text { attitudes }\end{array}$ & $\begin{array}{l}\text { Some people talk about } \\
\text { 'left', 'right' and 'centre' to } \\
\text { describe parties and }\end{array}$ & $\begin{array}{l}\text { In politics today, do you } \\
\text { consider yourself a: } \\
(-0.5) \text { Democrat }\end{array}$ \\
\hline
\end{tabular}




politicians. With this in (0) Independent
mind, where would you (0) Something else
place yourself on the
following scale?
(-0.5) Very left-wing
(-0.5) Fairly left-wing
(-0.5) Slightly left-of-centre
(0) Centre

(0.5) Slightly right-of-

centre

(0.5) Fairly right-wing

(0.5) Very right-wing

(NA) Don't know

Although the number of outlets included in both surveys is similar, the outlets themselves are different. As Table A4 shows, 16 outlets were included in both surveys, so the overlap is around 50\%-leaving considerable room for variation. The Pew survey did not typically include aggregator brands like Yahoo! and MSN, but because it did not specifically ask about online use, it did include radio shows (e.g., Rush Limbaugh and Sean Hannity).

Table A4. Outlets included in US datasets.

\begin{tabular}{ccc}
\hline Outlet & Data & $\begin{array}{c}\text { Pew American Trends } \\
\text { Panel survey (W57) }\end{array}$ \\
\hline ABC News & $\checkmark$ & $\checkmark$ \\
AOL News & $\checkmark$ & $\checkmark$ \\
BBC News & $\checkmark$ & \\
Being Liberal & $\checkmark$ & $\checkmark$ \\
Blaze & $\checkmark$ & \\
Breitbart & $\checkmark$ &
\end{tabular}




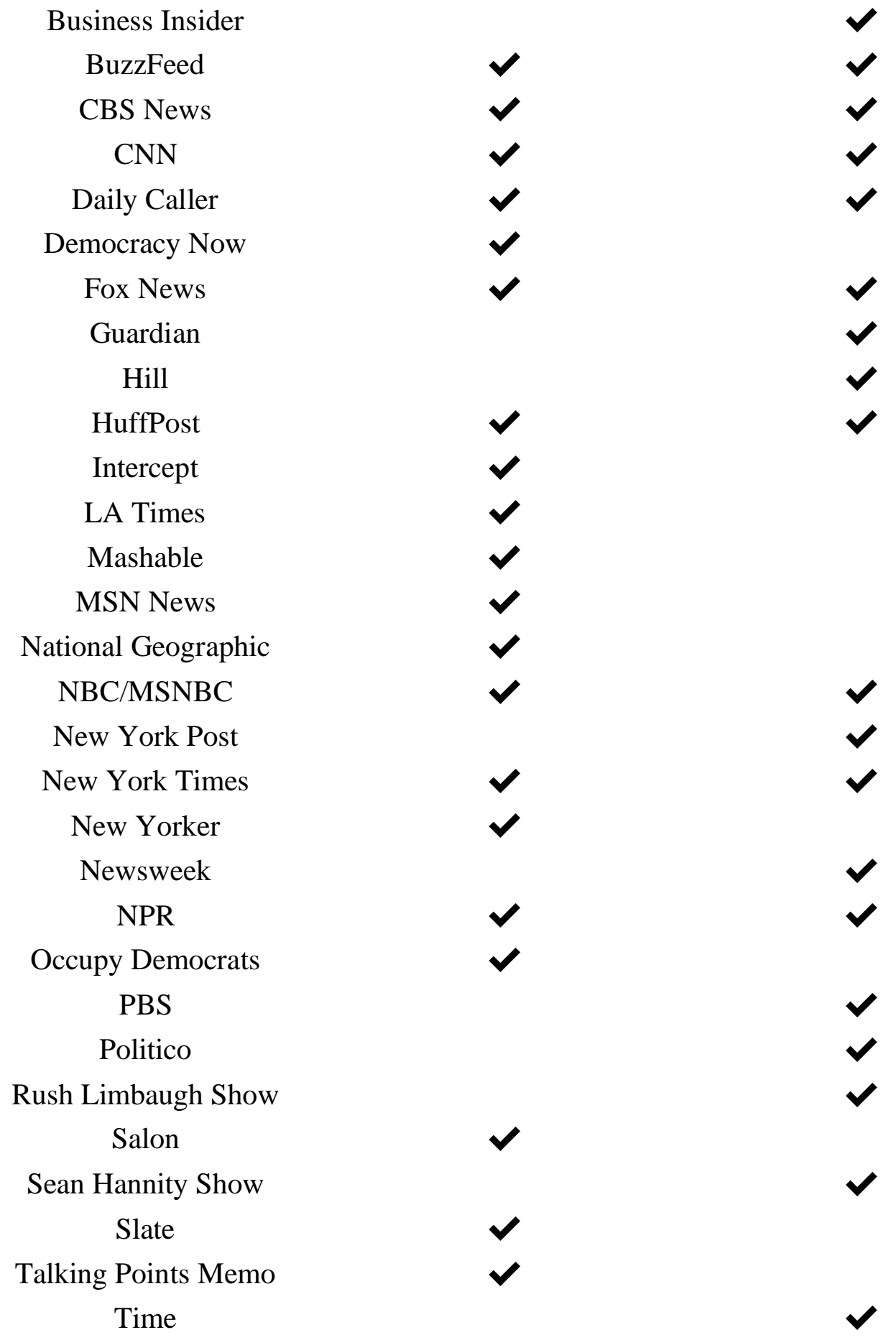




Univision
Upworthy
USA Today
Vanity Fair
Vice
Vox

Wall Street Journal

Washington Examiner

Washington Post

Yahoo! News

Note. Pew asked about NBC and MSNBC separately.

As described in an earlier subsection, despite differences in the way the political attitudes were measured, both surveys produced very similar outlet slant scores $(r=.98)$. But more importantly, despite differences in outlets that were included in the survey, the estimates of left and right echo chamber sizes are remarkably similar (Table A5). Estimates of the mean size of the right echo chamber are identical, as are the range. The average size of the left echo chamber is 3pp smaller in the Pew data, as is the top end of the range.

Table A5. Echo chambers in US datasets.

\begin{tabular}{ccccc}
\hline & \multicolumn{2}{c}{ Left } & \multicolumn{2}{c}{ Right } \\
\hline & Data & Pew & Data & Pew \\
\hline Mean & $10 \%$ & $7 \%$ & $3 \%$ & $3 \%$ \\
Range & $0-31 \%$ & $0-28 \%$ & $0-8 \%$ & $0-8 \%$ \\
\hline
\end{tabular}

\section{$U K$}

Table A6 compares the data from Kalogeropoulos et al. (2019) to the dataset used in the main analysis. The most important difference is that the data was collected through 
a YouGov Pulse desktop web tracking panel rather through an online survey. As such, the data is not based on recall and is largely free of social desirability and similar biases. The overlap between outlets tracked and included in the survey is high (Table A7), but it should also be noted that the tracking data is three years older than the survey data.

Table A6. Key differences between UK datasets.

\begin{tabular}{|c|c|c|}
\hline & Data & $\begin{array}{l}\text { Kalogeropoulos et al. } \\
(2019)\end{array}$ \\
\hline Fieldwork dates & Jan/Feb 2020 & Apr/May 2017 \\
\hline Mode & $\begin{array}{l}\text { Non-probability online } \\
\text { panel }\end{array}$ & $\begin{array}{l}\text { Desktop online tracking } \\
\text { panel (YouGov Pulse) }\end{array}$ \\
\hline Sample size & 2,011 & 3,192 \\
\hline Outlets & 19 & 21 \\
\hline News use measure & $\begin{array}{l}\text { Online news use in the last } \\
\text { week }\end{array}$ & $\begin{array}{l}\text { Accessed news domain in } \\
\text { the last month for at least } 5 \\
\text { seconds }\end{array}$ \\
\hline Political attitudes measure & $\begin{array}{l}\text { Some people talk about } \\
\text { 'left', 'right' and 'centre' to } \\
\text { describe parties and } \\
\text { politicians. With this in } \\
\text { mind, where would you } \\
\text { place yourself on the } \\
\text { following scale? } \\
(-0.5) \text { Very left-wing } \\
(-0.5) \text { Fairly left-wing } \\
(-0.5) \text { Slightly left-of- } \\
\text { centre } \\
\text { (0) Centre }\end{array}$ & None \\
\hline
\end{tabular}


(0.5) Slightly right-of-

centre

(0.5) Fairly right-wing

(0.5) Very right-wing

(NA) Don't know

Table A7. Outlets included in UK datasets.

\begin{tabular}{|c|c|c|}
\hline Outlet & Data & $\begin{array}{c}\text { Kalogeropoulos et al. } \\
\text { (2019) }\end{array}$ \\
\hline BBC News & $V$ & $\checkmark$ \\
\hline Breitbart & & $\checkmark$ \\
\hline BuzzFeed News & $\vee$ & $\checkmark$ \\
\hline Canary & & $\checkmark$ \\
\hline Channel 4 News & & $\checkmark$ \\
\hline Economist & $\checkmark$ & \\
\hline Evening Standard & & $\checkmark$ \\
\hline Express & $\checkmark$ & $\checkmark$ \\
\hline Financial Times & $\checkmark$ & \\
\hline Guardian & $\checkmark$ & $\checkmark$ \\
\hline HuffPost & $\checkmark$ & $\vee$ \\
\hline Independent & $\checkmark$ & $\checkmark$ \\
\hline ITV News & $\checkmark$ & $\vee$ \\
\hline Lad Bible & $\checkmark$ & $\checkmark$ \\
\hline MailOnline & $\checkmark$ & $\vee$ \\
\hline Metro & $\checkmark$ & $\checkmark$ \\
\hline Mirror & $\checkmark$ & $V$ \\
\hline MSN News & $\checkmark$ & $\checkmark$ \\
\hline Sky News & $\checkmark$ & $V$ \\
\hline Sun & $\checkmark$ & $\checkmark$ \\
\hline
\end{tabular}




\begin{tabular}{ccc} 
Telegraph & $\checkmark$ & $\checkmark$ \\
Times & $\checkmark$ & $\checkmark$ \\
Yahoo! News & $\checkmark$ & $\checkmark$ \\
\hline
\end{tabular}

The tracking dataset does not contain individual-level data on political attitudes, so the outlet slant scores from Fletcher et al. (2020) were used instead, as these were based on survey data collected just two months earlier. As with the US, the two different datasets produce very similar results, with only a 1-2pp difference between the average echo chamber sizes and ranges.

Table A8. Echo chambers in UK datasets.

\begin{tabular}{ccccc}
\hline & \multicolumn{2}{c}{ Left } & \multicolumn{2}{c}{ Right } \\
\hline & Data & $\begin{array}{c}\text { Kalogeropoulos } \\
\text { et al. (2019) }\end{array}$ & Data & $\begin{array}{c}\text { Kalogeropoulos } \\
\text { et al. (2019) }\end{array}$ \\
\hline Mean & $2 \%$ & $3 \%$ & $5 \%$ & $5 \%$ \\
Range & $0-6 \%$ & $0-7 \%$ & $0-10 \%$ & $0-12 \%$ \\
\hline
\end{tabular}

Of course, we are only able to offer two comparisons here, so it cannot be concluded that the data and the approach is robust to all different sets of outlets, measures of news use, measures of political attitudes, and data collection modes. The similarities may be largely coincidental. However, it does suggest that any variation is likely to be small and supports the idea that the formation of large echo chambers is largely precluded by fundamentally overlapping patterns of news media use.

\section{List of Outlets Analysed}

Table A9. Austria.

\begin{tabular}{ccc}
\hline Outlet & Relative slant & Online reach $(\%)$ \\
\hline Unzensuriert & 0.22 & 3.99 \\
Kronen Zeitung & 0.10 & 25.54 \\
oe24 & 0.08 & 11.52
\end{tabular}


Fletcher, Robertson, Nielsen

\begin{tabular}{|c|c|c|}
\hline Puls 4 & 0.04 & 6.83 \\
\hline ATV & 0.04 & 5.24 \\
\hline Heute.at & 0.03 & 12.27 \\
\hline Kronehit & 0.02 & 9.88 \\
\hline ORF News & 0.00 & 36.01 \\
\hline Kleine Zeitung & -0.01 & 9.08 \\
\hline Nachrichten.at & -0.01 & 6.58 \\
\hline Salzburger Nachrichten & -0.01 & 3.19 \\
\hline GMX News & -0.01 & 17.96 \\
\hline News.at & -0.02 & 5.69 \\
\hline ARD News & -0.02 & 5.24 \\
\hline NÖ Nachrichten & -0.02 & 4.74 \\
\hline MSN News & -0.03 & 7.18 \\
\hline Mein Bezirk & -0.03 & 12.27 \\
\hline Kurier & -0.04 & 12.12 \\
\hline ZDF News & -0.04 & 5.24 \\
\hline Yahoo! News & -0.06 & 5.19 \\
\hline Vorarlberger Nachrichten & -0.06 & 1.40 \\
\hline Die Presse & -0.07 & 9.33 \\
\hline Info Direkt & -0.09 & 2.09 \\
\hline Profil & -0.10 & 4.04 \\
\hline Tiroler Tageszeitung & -0.11 & 4.59 \\
\hline Wiener Zeitung & -0.13 & 3.04 \\
\hline Der Standard & -0.18 & 16.06 \\
\hline Kontrast & -0.21 & 4.04 \\
\hline Falter & -0.23 & 2.99 \\
\hline
\end{tabular}

Table A10. Denmark.

\begin{tabular}{ccc}
\hline Outlet & Relative slant & Online reach (\%) \\
\hline Den Korte Avis & 0.22 & 3.88
\end{tabular}




\begin{tabular}{ccc} 
Børsen & 0.14 & 6.16 \\
Berlingske & 0.11 & 10.29 \\
Jyllands-Posten & 0.08 & 11.40 \\
Dagens.dk & 0.05 & 6.31 \\
Søndagsavisen & 0.05 & 2.62 \\
TV2 News & 0.02 & 29.69 \\
BT & 0.01 & 25.67 \\
Ekstra Bladet & 0.00 & 28.82 \\
Kristeligt Dagblad & 0.00 & 3.59 \\
Weekendavisen & 0.00 & 3.20 \\
DR News & -0.01 & 34.50 \\
Radio4 & -0.02 & 2.81 \\
Altinget & -0.03 & 5.87 \\
MSN News & -0.04 & 3.44 \\
Fagblade & -0.06 & 2.96 \\
Avisen.dk & -0.06 & 5.68 \\
Zetland & -0.08 & 3.35 \\
Politiken & -0.11 & 13.93 \\
Information & -0.16 & 5.77 \\
\hline
\end{tabular}

\section{Table A11. Germany.}

\begin{tabular}{ccc}
\hline Outlet & Relative slant & Online reach $(\%)$ \\
\hline Tichys Einblick & 0.28 & 3.58 \\
Epoch Times & 0.20 & 2.34 \\
Compact & 0.13 & 2.04 \\
Junge Freiheit & 0.13 & 3.03 \\
Bild & 0.09 & 13.97 \\
Sat.1 News & 0.07 & 2.19 \\
N24 & 0.07 & 7.86 \\
Die Welt & 0.06 & 8.80
\end{tabular}


Fletcher, Robertson, Nielsen

$\begin{array}{ccc}\text { RTL News } & 0.06 & 3.43 \\ \text { HuffPost } & 0.05 & 2.49 \\ \text { n-tv } & 0.05 & 9.90 \\ \text { t-online News } & 0.04 & 14.27 \\ \text { Web.de News } & 0.04 & 11.93 \\ \text { Focus } & 0.03 & 12.33 \\ \text { GMX News } & 0.02 & 11.44 \\ \text { ARD News } & -0.02 & 15.27 \\ \text { ZDF News } & -0.02 & 6.81 \\ \text { Handelsblatt } & -0.03 & 5.07 \\ \text { Yahoo! News } & -0.04 & 4.57 \\ \text { MSN News } & -0.05 & 4.97 \\ \text { Stern } & -0.06 & 6.81 \\ \text { FAZ } & -0.07 & 5.57 \\ \text { Der Spiegel } & -0.08 & 17.01 \\ \text { deutsche Zeitung } & -0.11 & 8.70 \\ \text { Die Zeit } & -0.16 & 10.34\end{array}$

Table A12. Norway.

\begin{tabular}{ccc}
\hline Outlet & Relative slant & Online reach $(\%)$ \\
\hline Document.no & 0.35 & 7.11 \\
Resett & 0.31 & 8.56 \\
HRS & 0.28 & 4.83 \\
Nettavisen & 0.10 & 25.57 \\
Dagens Næringsliv & 0.06 & 10.35 \\
TV2 News & 0.05 & 27.56 \\
ABC Nyheter & 0.05 & 12.29 \\
MSN News & 0.04 & 4.98 \\
P4 & 0.03 & 4.23 \\
NRK News & 0.00 & 33.58
\end{tabular}




\begin{tabular}{ccc} 
VG & 0.00 & 50.05 \\
Vårt Land & 0.00 & 1.94 \\
Aftenposten & -0.01 & 22.64 \\
Bergens Tidende & -0.02 & 9.80 \\
Dagbladet & -0.05 & 31.39 \\
Yahoo! News & -0.07 & 2.14 \\
Adresseavisen & -0.13 & 5.92 \\
Dagsavisen & -0.15 & 5.77 \\
Nationen & -0.16 & 1.84 \\
Filter Nyheter & -0.16 & 2.19 \\
Morgenbladet & -0.21 & 2.59 \\
Klassekampen & -0.24 & 3.58 \\
\hline
\end{tabular}

Table A13. Spain.

\begin{tabular}{ccc}
\hline Outlet & Relative slant & Online reach $(\%)$ \\
\hline COPE & 0.27 & 7.43 \\
Libertad & 0.22 & 7.83 \\
OKDiario & 0.20 & 12.46 \\
ABC & 0.17 & 10.72 \\
La Razón & 0.16 & 8.82 \\
El Español & 0.11 & 7.98 \\
El Mundo & 0.10 & 18.05 \\
Voz de Galicia & 0.10 & 5.63 \\
Onda Cero & 0.09 & 4.69 \\
Cinco Días & 0.09 & 2.84 \\
Marca & 0.08 & 12.81 \\
Euronews & 0.07 & 3.59 \\
Antena 3 News & 0.06 & 15.15 \\
Expansión & 0.06 & 3.84 \\
El Catalán & 0.06 & 2.14
\end{tabular}


Fletcher, Robertson, Nielsen

\begin{tabular}{|c|c|c|}
\hline Digital Sevilla & 0.05 & 3.64 \\
\hline Nius Diario & 0.05 & 2.64 \\
\hline As & 0.03 & 5.73 \\
\hline Yahoo! News & 0.02 & 8.67 \\
\hline El Confidencial & 0.02 & 14.31 \\
\hline RTVE News & 0.01 & 10.77 \\
\hline Telecinco & 0.01 & 10.97 \\
\hline MSN News & 0.00 & 6.88 \\
\hline El Independiente & -0.02 & 6.08 \\
\hline Cuatro & -0.03 & 5.53 \\
\hline 20minutos & -0.03 & 17.65 \\
\hline EFE & -0.03 & 4.69 \\
\hline El Orden Mundial & -0.03 & 2.34 \\
\hline BuzzFeed News & -0.05 & 2.29 \\
\hline El País & -0.05 & 23.53 \\
\hline La Vanguardia & -0.05 & 11.81 \\
\hline El Nacional & -0.05 & 3.19 \\
\hline El Periódico & -0.07 & 9.47 \\
\hline El Diario & -0.07 & 16.65 \\
\hline Maldita & -0.08 & 2.49 \\
\hline Cadena SER & -0.09 & 9.27 \\
\hline La Sexta & -0.10 & 11.52 \\
\hline La Republica & -0.11 & 3.09 \\
\hline Diario Público & -0.17 & 7.88 \\
\hline Europa Press & -0.17 & 7.88 \\
\hline HuffPost & -0.21 & 7.28 \\
\hline
\end{tabular}

Table A14. UK.

\begin{tabular}{ccc}
\hline Outlet & Relative slant & Online reach $(\%)$ \\
\hline Express & 0.24 & 2.78
\end{tabular}




\begin{tabular}{ccc} 
MailOnline & 0.18 & 15.91 \\
Sun & 0.15 & 5.67 \\
Telegraph & 0.12 & 7.01 \\
Sky News & 0.11 & 9.75 \\
MSN News & 0.06 & 5.62 \\
ITV News & 0.06 & 3.23 \\
Times & 0.02 & 4.08 \\
BBC News & 0.01 & 47.29 \\
Yahoo! News & -0.02 & 5.42 \\
Financial Times & -0.06 & 2.14 \\
Metro & -0.07 & 4.48 \\
Mirror & -0.10 & 4.53 \\
Economist & -0.15 & 2.04 \\
Lad Bible & -0.17 & 4.18 \\
Guardian & -0.22 & 19.24 \\
BuzzFeed News & -0.23 & 6.22 \\
HuffPost & -0.23 & 6.91 \\
Independent & -0.27 & 6.61 \\
\hline
\end{tabular}

Table A15. US.

\begin{tabular}{ccc}
\hline Outlet & Relative slant & Online reach (\%) \\
\hline Breitbart & 0.32 & 6.47 \\
Fox News & 0.25 & 17.66 \\
Daily Caller & 0.22 & 5.21 \\
Blaze & 0.21 & 5.50 \\
AOL News & -0.03 & 5.74 \\
Yahoo! News & -0.05 & 19.76 \\
MSN News & -0.06 & 11.19 \\
ABC News & -0.06 & 9.93 \\
CBS News & -0.06 & 9.68
\end{tabular}


Fletcher, Robertson, Nielsen

\begin{tabular}{ccc} 
Wall Street Journal & -0.08 & 8.61 \\
National Geographic & -0.08 & 4.33 \\
USA Today & -0.10 & 9.10 \\
NBC News & -0.14 & 13.43 \\
BuzzFeed News & -0.17 & 13.87 \\
CNN & -0.19 & 20.19 \\
New York Times & -0.21 & 18.10 \\
Vanity Fair & -0.21 & 3.07 \\
LA Times & -0.22 & 5.64 \\
Occupy Democrats & -0.22 & 4.43 \\
Washington Post & -0.23 & 15.18 \\
HuffPost & -0.24 & 16.06 \\
Vice News & -0.26 & 5.99 \\
NPR & -0.26 & 11.05 \\
New Yorker & -0.26 & 5.50 \\
Upworthy & -0.28 & 2.77 \\
Vox & -0.29 & 8.42 \\
Salon & -0.31 & 3.84 \\
Mashable & -0.32 & 2.82 \\
Democracy Now & -0.33 & 3.99 \\
Slate & -0.34 & 5.64 \\
\hline
\end{tabular}

Journal of Quantitative Description: Digital Media 1(2021) 56 